\title{
The effect of reproductive state on activity budget, feeding behavior, and urinary C-peptide levels in wild female Assamese macaques
}

\author{
Sonia Touitou ${ }^{1,2,3}$ D $\cdot$ Michael Heistermann ${ }^{4} \cdot$ Oliver Schülke $^{1,2,3} \mathbb{D} \cdot$ Julia Ostner ${ }^{1,2,3} \mathbb{D}$
}

Received: 11 February 2021 / Revised: 13 July 2021 / Accepted: 15 July 2021

(c) The Author(s) 2021, corrected publication 2022

\begin{abstract}
The source of maternal energy supporting reproduction (i.e., stored or incoming) is an important factor determining different breeding strategies (capital, income or mixed) in female mammals. Key periods of energy storage and allocation might induce behavioral and physiological shifts in females, and investigating their distribution throughout reproduction helps in determining vulnerable phases shaping female reproductive success. Here, we examined the effects of reproductive state on activity budget, feeding behavior, and urinary C-peptide ( $\mathrm{uCP}$ ) levels, a physiological marker of energy balance, in 43 wild female Assamese macaques (Macaca assamensis). Over a 13-month study period, we collected 96,266 instantaneous records of activity and 905 urine samples. We found that early lactating females and non-gestating-non-lactating females follow an energy-saving strategy consisting of resting more at the expense of feeding and consuming mostly fruits which contributed to enhancing their energy intake and feeding efficiency. We found an opposite pattern in gestating and late lactating females who feed more at the expense of resting and consume mostly seeds, providing a fiber-rich diet. Storing food into cheek pouches increased throughout gestation while it decreased all along with lactation. Lastly, we found the highest uCP levels during late gestation. Our results reflect different feeding adaptations in response to the energetic costs of reproduction and suggest a critical role of fat accumulation before conception and metabolizing fat during gestation and lactation. Overall, our study provides an integrative picture of the energetics of reproduction in a seasonal species and contributes to our understanding of the diversity of behavioral and physiological adaptations shaping female reproductive success.
\end{abstract}

\section{Significance statement}

To offset their substantial energetic investment in reproduction, mammalian females may modify their behavior and the way they extract energy from their environment. In addition, as a result of heightened energy expenditure, female reproduction might trigger physiological shifts. To date, most studies investigated the energetic costs of female reproduction using either a behavioral or a physiological approach. To arrive at a more comprehensive picture, we combined behavioral data with a physiological marker of energy balance, i.e., urinary C-peptide, in a seasonal primate species in its natural habitat. Our results indicate that throughout the reproductive cycle, behavioral and physiological adaptations operate concomitantly, inducing modifications in female activity budget, feeding behavior, and suggesting shifts in fat use. Overall, our results illustrate the relevance of combining data on behavior and hormones to investigate breeding strategies in coping with the energetic costs of reproduction.

Keywords Reproduction · Activity budget $\cdot$ Diet composition $\cdot$ Energy intake $\cdot$ Feeding efficiency $\cdot$ Urinary C-peptide

Communicated by K. Langergraber.

Sonia Touitou

touitou.sonia@gmail.com

1 Department of Behavioral Ecology,

Johann-Friedrich-Blumenbach Institute for Zoology and Anthropology, Georg-August University Goettingen, Goettingen, Germany
2 Leibniz ScienceCampus Primate Cognition, Goettingen, Germany

3 Primate Social Evolution Group, German Primate Centre, Leibniz Institute for Primate Research, Goettingen, Germany

4 Endocrinology Laboratory, German Primate Centre, Leibniz Institute for Primate Research, Goettingen, Germany 


\section{Introduction}

In comparison to males, female mammals bear most of the energetic costs of reproduction as they have to meet the nutritional requirements of gestation and lactation (Gittleman and Thompson 1988; Prentice and Prentice 1988). This major maternal investment allocated to reproduction can lead to a negative energy balance, i.e., energy expenditure exceeding energy input (Hall et al. 2012), with subsequent drastic repercussions on the mother's fitness. For example, females lose weight during lactation in numerous species (humans: Guillermo-Tuazon et al. 1992; Columbian ground squirrels (Spermophilus columbianus): Neuhaus 2000; domestic pigs (Sus domesticus): Tantasuparuk et al. 2001; bonnet macaques (Macaca radiata): Cooper et al. 2004). This energy deficiency in reproducing females can make females more vulnerable when facing adverse situations, such as food shortages, infection, or injuries (Festa-Bianchet 1989; Gould et al. 2003; Archie et al. 2014; East et al. 2015). As a result of the energetic expense, reproducing females may decrease their investment in future reproduction or may forego it altogether (Koivula et al. 2003). As stated by life history theory (Stearns 1992), reproduction is, therefore, a tradeoff between current reproductive investment and future fitness (Clutton-Brock et al. 1989; Koivula et al. 2003; Altmann and Alberts 2005; Festa-Bianchet et al. 2019).

Various adaptations evolved in response to the energetic load of reproduction to minimize its fitness-threatening consequences. Reproducing females may modify their activity budget, for example by increasing the time they spend resting in order to save energy and offset the costs of reproduction (Goldberg et al. 1991; Barrett et al. 2006; Gamo et al. 2013). Additionally, the increased energy requirements of reproduction can be met through modifications in female feeding behavior. Three main feeding strategies to maximize intake have been described: females can feed longer, faster, or more selectively (Lee 1987). A female can devote more time to feeding, at the expense of other behaviors, in order to support her current requirements (Dunbar and Dunbar 1988). Besides increasing feeding time, a female can also increase her feeding efficiency, i.e., the nutrient intake per unit of feeding time. To do so, a female can either increase ingestion rate for the same food (Schülke et al. 2006) or select food with higher nutrient density, modifying diet composition toward specific nutrient requirements (Mellado et al. 2005). These three feeding strategies have been observed in gestating and/or lactating females in various mammalian species (Logan and Sanson 2003; McCabe and Fedigan 2007; Clutton-Brock et al. 2009). Overall, reproducing females increase their energy intake, reduce their energy expenditure, or both, depending on whether their strategy consists of building up fat stores or reinvesting incoming energy immediately into reproduction.

Another major adaptation to cope with the energetic costs of reproduction relies on the timing of reproductive events relative to variation in food abundance. Mammals living in habitats with seasonally fluctuating resources show temporal patterns in the scheduling of breeding events (Jönsson 1997; introduced first in birds: Drent and Daan 1980). At one extreme of the seasonal breeding spectrum are capital breeders that rely on endogenous condition, building up fat stores during the rich season before they breed, and using that maternal capital to invest in offspring during the lean season (e.g., bighorn ewes (Ovis Canadensis): Festa-Bianchet et al. 1998). At the other extreme, income breeders mate prior to the peak of food availability to synchronize lactation with the period of the highest environmental energy supply, so that income can be immediately reinvested in the offspring (e.g., Antarctic fur seals (Arctocephalus gazelle): Oftedal et al. 1987). These strategies are not mutually exclusive, as some species use a mixed strategy when timing their reproductive events (Koenig et al. 1997; Wheatley et al. 2008). Investing or not in reproductive effort depending on current and/or future food resources is thus an adaptation to maximize reproductive success by offsetting the costs of reproduction with stored and/or incoming energy sources.

Contrary to strict income or capital breeders, relatively little is known about the suite of adaptations to the energetic costs of reproduction in mammals following a mixed breeding strategy. With our study, we aim at contributing to start filling this gap. Mixed breeding strategies have been described in several primate species (Brockman and van Schaik 2005), making primates a suitable model for our study on the energetics of mammalian female reproductive strategies. Primates are also interesting in this respect as they experience comparatively high costs of reproduction, which should be reflected physiologically and behaviorally. Reproduction is particularly costly in primates, as females give birth to well-developed and large-brained neonates relative to maternal body size and birth weight, making infants energetically more expensive to produce compared to nonprimate taxa (Bennett and Harvey 1985). Once born, neonates require considerable maternal investment before the main phases of brain development are achieved and before the infant reaches a critical mass to insure independence at weaning age (Lee et al. 1991; Martin 1996). To account for these costs, gestation and lactation are longer in primates, with slower rates of fetal and neonatal growth compared to other mammals of similar body size (Dufour and Sauther 2002). Spreading gestation and lactation over time lowers the daily energetic load and allows more metabolic and physiological flexibility when coping with reproduction and its energy requirements (Payne and Wheeler 1968; Dufour and 
Sauther 2002). Still, the costs of reproduction are substantial in primates, especially during lactation which is associated with important maternal energy constraints to support milk production and infant carrying (Tardiff 1997; Hinde and Milligan 2011). Above all, the extended durations of gestation and lactation in primates allow the investigation of potential critical periods in terms of energetic costs within reproductive states.

The energetic costs of female reproduction are reflected physiologically and can be assessed from concentrations of urinary C-peptide of insulin ( $\mathrm{uCP}$ ), a non-invasive marker of energy balance in primates (Sherry and Ellison 2007; Deschner et al. 2008; Emery et al. 2008; Girard-Buttoz et al. 2011; Fürtbauer et al. 2020). The C-peptide originates from the pancreas where it is cleaved from the inactive proinsulin and released into the bloodstream together with active insulin. Thus, measuring C-peptide concentration in urine provides an indirect assessment of insulin production (Melani et al. 1970; Meistas et al. 1982). The few studies linking $\mathrm{uCP}$ and female reproduction in primates found $\mathrm{uCP}$ levels to be unchanged across the reproductive cycle (Grueter et al. 2014; Bergstrom et al. 2020), higher during gestation (McCabe and Emery Thompson 2013; Nurmi et al. 2018; Fürtbauer et al. 2020), or lower during lactation (Ellison and Valeggia 2003; Emery Thompson et al. 2012). Female energy balance, therefore, seems to be affected differentially by reproductive states across species. The discrepancy of results might be explained by distinct breeding strategies and associated differences in behavioral adaptations throughout the reproductive cycle. Combining uCP levels and behavioral measures of energy balance aids in providing a comprehensive picture of the different ways females cope with reproduction. This may help towards a better understanding of the interrelationship between behavioral and physiological adaptations related to female reproductive energetics across the various reproductive strategies.

Here, we investigate the coping mechanisms in the face of the energetic costs of female reproduction in a wild primate population following a mixed breeding strategy. To do so, we compared potential behavioral and physiological differences both between and within reproductive states. To our knowledge, to date, only one study investigated the effect of female reproductive state on both behavioral and $\mathrm{uCP}$ measures (Cano-Huertes et al. 2017). Such an integrated approach not only sheds more light on behavioral adaptations when coping with gestation or lactation but also provides an estimation of the physiological costs of reproduction by inspecting whether or not gestation and lactation are associated with changes in energy balance. Assamese macaques (Macaca assamensis) are reproductively seasonal and follow a mixed breeding strategy as they have been classified as relaxed-income breeders with food abundance prior to the mating season mediating conception rate and the birth peak occurring during a period of high food availability (Brockman and van Schaik 2005; Heesen et al. 2013). Although $79 \%$ of births occur in a 3-month period (JO and OS unpublished data), in a given year, births often are spread over five months. The habitat does not allow females to reproduce every single year. Females who conceive early in the year are able to reproduce again late in the following year; otherwise, they typically skip a year (Fürtbauer et al. 2010). In any case, the interbirth interval is longer than 12 but shorter than 24 months, which prohibits a strict income breeding strategy of aligning peak needs with peak resource abundance. As a result, in mixed breeders such as Assamese macaques, strategies to support reproduction cannot be perfectly tied to the environment but rather to the respective reproductive schedule of each female.

The study population of Assamese macaques offers two advantages for the purpose of our study. First, as a consequence of their mixed breeding strategy and lack of strong synchrony in conceptions during the mating season, reproductive events and seasonality in food availability are not completely confounded. This is particularly well illustrated by visualizing the temporal succession of reproductive states for each female throughout a year (Fig. 1). Note, for example, that all possible reproductive states overlap in November, December, and May (gestating, lactating, and non-gestating-non-lactating), allowing us to study the energetic costs of reproduction in a seasonal primate species while controlling for ecological factors. This is critical since food availability induces changes in feeding behavior,

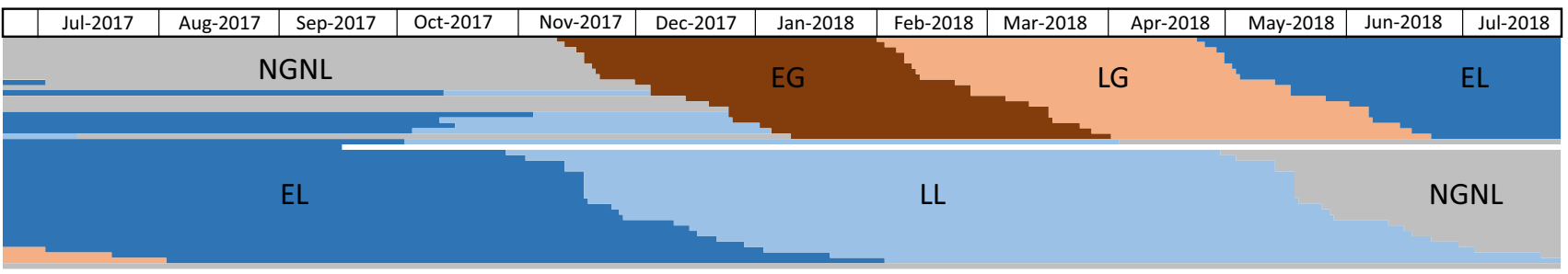

Fig. 1 Temporal succession of reproductive states (EG: early gestation; LG: late gestation; EL: early lactation; LL: late lactation; NGNL: non-gestating-non-lactating) for each focal female during the study period (July 2017 to July 2018). Each row represents one female (43 females in total) and the colors stand for the five different reproductive states 
energy balance and, thus, uCP levels in primates (Knott 1998; Sherry and Ellison 2007; Tsuji et al. 2008; Harris et al. 2009; Heesen et al. 2013; Lambert and Rothman 2015).

Second, cercopithecine primates, such as macaques, have cheek pouches used for storing intact food items for later consumption. Filling pouches is a feeding strategy ensuring rapid harvesting of a large quantity of food items that can be carried, processed, and ingested away from co-feeding sites and therefore, increasing feeding efficiency (Lambert 2005). The use of cheek pouches has been investigated particularly with regards to feeding competition avoidance in primates (Lambert 2005; Buzzard 2006), including the study population (with increased cheek pouch use in low-ranking females; Heesen et al. 2014). Surprisingly, to date, very few studies have examined a potential effect of female reproductive state on cheek pouch use. Using cheek pouches to store valuable, contestable food items may be a coping mechanism to offset, for example, the substantial costs of lactation (Hayes et al. 1992) in the face of feeding competition.

We investigated the coping mechanisms used to offset the energetic costs of different female reproductive states in Assamese macaques comparing different metrics. We first investigated female activity budgets, as reproductive state-dependent trade-offs in activity have been observed in female primates (Muruthi et al. 1991). Second, we examined how females spend their feeding time in terms of diet composition or feeding efficiency across reproductive states. Specifically, we quantified female diet composition in order to evaluate whether females feed more selectively at certain stages of their reproductive cycle by selecting specific nutrients from their habitat, such as digestible carbohydrates (e.g., fruits; Murray et al. 2009) and/or proteins (Herrera and Heymann 2004; Miller et al. 2006). Additionally, we considered the proportion of time females used their cheek pouches as a complementary feeding strategy to store specific and valuable nutrients. Third, we further dissected the nutritional impact of diet by calculating female energy and protein intake to capture potential differences between reproductive states (Muruthi et al. 1991; Miller et al. 2006). Relating energy intake to total feeding observations, we compared feeding efficiency between reproductive states (Muruthi et al. 1991; Serio-Silva et al. 1999). Lastly, we focused on female physiology and assessed female energy balance during the reproductive cycle using the measurements of uCP levels.

Controlling for the potential effects of ecological factors (fruit availability in the habitat) and travel distance (to account for potential behavioral and/or physiological shifts relative to physical activity), we tested the following predictions. We predicted that gestating and lactating females would exhibit different activity budgets than non-gestating-non-lactating females (prediction 1); lactating females in particular were expected to allocate more time to resting at the expense of feeding to conserve energy (Heesen et al. 2013). Gestating and lactating females were also predicted to change their diet composition to support their higher energetic requirements (prediction 2), feeding selectively by consuming more food items rich in sugar (e.g., fruits) and biasing their diet towards food items with high protein content (e.g., young leaves). We also expected gestating and lactating females to use their cheek pouches more than non-gestating-non lactating females (prediction 3). We predicted that gestating and lactating females had higher energy intake (prediction 4) and higher protein intake than nongestating-non-lactating females (prediction 5). Additionally, we expected gestating and lactating females to optimize their energy intake per unit of feeding time and therefore, to be more efficient than females outside of gestation or lactation when feeding in general (prediction 6) and when feeding on proteins (prediction 7). Finally, we expected to find the lowest uCP levels in lactating females, as their behavioral strategies to overcome the lactation load would not preclude them from losing weight (prediction 8; Heesen et al. 2013). To account for variation in reproductive costs within a reproductive state, we divided gestation and lactation periods into an early and a late phase of equal length. We expected the second phase of gestation (Durnin 1991) and particularly the first phase of lactation, which comprises the peak of lactation in our study population (Berghänel et al. 2016), to be the costliest periods. Thus, the above predicted patterns should be stronger in the early phase of lactation and the late phase of gestation, and early lactation should have the strongest effect of all reproductive states. Overall, as a consequence of their mixed breeding strategy, female Assamese macaques should go through periods of energy storage, energy-saving, and energy loss, and we aim at understanding the timing of these periods relative to reproduction.

\section{Materials and methods}

\section{Study site and subject}

The study was conducted at Phu Khieo Wildlife Sanctuary (PKWS) in Northeastern Thailand $\left(16^{\circ} 05^{\prime}\right.$ to $16^{\circ} 35^{\prime} \mathrm{N}$, $101^{\circ} 20$ to $\left.101^{\circ} 55^{\prime} \mathrm{E}\right)$. The sanctuary covers an area of more than $1650 \mathrm{~km}^{2}$ and the study site (Huai Mai Sot Yai, $16^{\circ} 27^{\prime} \mathrm{N}, 101^{\circ} 38^{\prime} \mathrm{E}, 600$ to $800 \mathrm{~m}$ above sea level) comprises dry evergreen forest with patches of dry dipterocarp forest and bamboo stands (Borries et al. 2002). The vegetation is dense; the terrain hilly and the habitat exhibit two distinct seasons, with a rainy season from March to October and a dry season from November to February (Richter et al. 2016). The mean annual temperature is $21.2^{\circ} \mathrm{C}$, with daily minimum temperatures ranging from $5.4{ }^{\circ} \mathrm{C}$ in the dry season to $23.2{ }^{\circ} \mathrm{C}$ in the rainy season (Borries et al. 2011; 
Richter et al. 2016). The annual amount of rainfall averages $1140 \mathrm{~mm}$ (Borries et al. 2011).

The study covered a 13-month period (July 2017-July 2018) and was conducted on 43 adult females belonging to three neighboring study groups. One adult female died in September 2017. At the onset of the study, each group was composed of several adult males $(9,6$, and 3 , respectively), several adult females $(20,13$, and 9 , respectively), and a large number of immatures. Females in the study population breed seasonally, with a mating season from October to February, and a birth season from April to July (Fürtbauer et al. 2010). A female was considered adult at the onset of the mating season of her first conception (which usually occurs at about 5.5 years of age). Three females that were nulliparous at the onset of the study period (and therefore were-strictly speaking-not yet categorized as adult at this time prior to the mating season) were included as focal "adult" females as they were about to conceive for the first time (and to become adult) during the 2017-2018 mating season. Two old females were discarded from the study, as they had not conceived for at least the last 6 years and thus seemed to have become reproductively inactive.

\section{Reproductive states}

We considered five reproductive states: early gestation (EG), late gestation (LG), early lactation (EL), late lactation (LL), and a non-gestating-non-lactating state (NGNL). Lactation lasts a year and we differentiated EL (first 6 months) from LL (last 6 months), as we observed more frequent infant suckling at daytime during EL (Berghänel et al. 2016), making this early phase of lactation a potentially more energetically costly period for the mother. Gestation lasts on average 164 days (Fürtbauer et al. 2010), and was also split in half, since the energy requirements in the second half of gestation have been shown to be higher, as illustrated by high levels of thyroid hormones and glucocorticoids (Touitou et al. 2021).

When the exact date of parturition was unknown, we assigned the birth date based on visual criteria of the infant, and on the last day, we saw the mother not carrying a newborn. Once the date of parturition was known (37\% of the births) or estimated (with a certainty of \pm 1 week in $75 \%$ of the cases), we back-counted 164 days to pinpoint the date of conception. To avoid confounding energy requirements of simultaneous reproductive states, we discarded some data coming from five females when they were going through two different reproductive states at the same time (gestating while still nursing the last infant).

\section{Behavioral data collection}

We followed a group for several days in a row (a "sampling block"). As the number of focal females differed substantially between groups, we accordingly attributed different sampling effort to each of the three groups (on average 16, 13, and 8 consecutive sampling days per respective group from the largest to the smallest). The interval between two consecutive sampling blocks for the same group was on average 28.5 days (range: 18 to 48 days). We evenly distributed those sampling blocks for each group across the study period (9 to 10 per group).

Behavioral data were collected on female subjects from dawn to dusk and sleep tree to sleep tree (average \pm SE: $8.1 \pm 0.4$ focal animal sampling hours collected per day). It was not possible to record data blind as our study involved focal animals. We performed 40-min focal animal sampling during which instantaneous records were collected at 2-min intervals $(96,266$ data points in total and 232.5 \pm 4.8 (average \pm SE) data points per female and sampling block). An effort was made to evenly distribute focal sampling across females and time of day.

During the instantaneous data collection, we recorded the focal female's activity, i.e., whether she was feeding (ingesting, chewing food), traveling (vertical or horizontal locomotion), resting (being stationary and not doing anything else), or involved in a social activity (grooming, being groomed, mating, etc.). Assessing such a complete activity budget allows the determination of potential tradeoffs between behaviors during the female reproductive cycle. For each instantaneous record, we also recorded whether the focal female was feeding from her cheek pouches (typically recognizable by the female pressing the outer part of her cheek with her hand or shoulder to move food item from the cheek pouch into the mouth) or not. Putting food into the cheek pouches was recorded as feeding whereas feeding from the cheek pouches was not, to avoid redundancy.

\section{Diet composition}

For each feeding event, we recorded the food item ingested. Assamese macaques are mainly frugivorous, with fruits (pulp or full fruit) and seeds representing up to $59 \%$ of their diet (Heesen et al. 2013). Additionally, they also feed on animal matter (insects, spiders, mollusks, small reptiles, etc.), leaves, and more rarely on flowers, bark, mushrooms, and roots (Heesen et al. 2013). For each feeding event involving a plant food item, we recorded the species ingested if known (88\% of cases) and the plant part (fruit, pulp, seed, leaf, or flower) together with its state of maturity. We summarized per sampling block the proportion of all feeding records spent on consuming the main food item categories fruits, seeds, young leaves, and animal matter, leaving the category "other items" for rarely consumed food items. 


\section{Ingestion rate, nutritional analysis, and energy intake calculation}

From the instantaneous records, we used the relative frequency of feeding per female, among all other activities, that we multiplied by $630 \mathrm{~min}$ (i.e., the average active day length) to estimate the average duration of feeding on each plant food item in a day. When possible, we recorded ingestion rate data in order to assess the average quantity of plant food units (full fruit, seed, bite, handful of leaves, etc.) ingested per minute.

Plant food items were collected, processed in the camp (to keep only the part consumed by the monkeys), and their respective units (same as the one used to calculate ingestion rate) were weighed to estimate wet unit weight ingested per minute. Additional plant samples were kept frozen $\left(-19^{\circ} \mathrm{C}\right)$ until transport to the Animal Nutrition Laboratory of the Department of Animal Science, Kasetsart University, Bangkok where their nutritional content was measured.

From the nutritional analyses, the proportions, in dry matter, of crude protein, crude fat, neutral detergent fiber (NDF), total non-structural carbohydrates, and ash, were determined together with the percentage of moisture. Considering that carbohydrates and protein provide $4 \mathrm{kcal} / \mathrm{g}$, fat $9 \mathrm{kcal} / \mathrm{g}$ and NDF $3 \mathrm{kcal} / \mathrm{g}$ with $52 \%$ being transformed into energy (Conklin-Brittain et al. 2006; Sawada et al. 2010; Heesen et al. 2013), we were able for each plant food item analyzed to assess its energy content in $\mathrm{kJ} / \mathrm{g}$ of dry matter (with $1 \mathrm{kcal}=4.184 \mathrm{~kJ}$ ).

We used the percentage of moisture to calculate the dry unit weight out of the wet unit weight. The dry unit weight of one unit was then multiplied by the respective food item's ingestion rate and energy content to get the energy yield (in $\mathrm{kJ} / \mathrm{min}$ ) of the item. In total, we were able to determine the energy yield for 43 different plant food items. We multiplied energy yield by the estimated duration (in min/day) during which the female was feeding on the respective item during a sampling block to obtain the energy intake (in $\mathrm{kJ} /$ day) coming from each important plant food item, which we further summed up to assess the energy intake for each female within each sampling block. We additionally followed the exact same procedure but focusing only on the protein part of each plant food item to get an approximation of the protein intake (in g/day) of each female within each sampling block.

We considered our estimation of energy intake (and therefore protein intake) reliable when it was calculated from at least $60 \%$ of the total feeding observations per female and per sampling block. In cases where energy data were available for less than $60 \%$, the respective female in the respective sampling block was discarded from the analysis on nutritional intake. In the remaining cases, our assessments of energy and protein intakes relied on about $75 \%$ of a female's feeding observations. For further details on our energy intake calculation, see Touitou et al. (2021).

Among the 32 important plant food items consumed during the study period (items which respectively represented at least $5 \%$ of the total feeding observations in a sampling block), we were able to get the energy yield for 24 of them (i.e., 75\%). The other 8 items were consumed for more than $5 \%$ of feeding time (range 5-15\%) only during a single sampling block each.

\section{Feeding efficiency for energy and protein}

In order to assess the amount of energy a female ingested per unit of feeding time within one sampling block, and thus her feeding efficiency, we divided energy intake by the number of feeding observations from which we calculated the respective energy intake (referred to as energetic feeding efficiency in the following). We also considered a female's feeding efficiency when ingesting plant protein matter (protein feeding efficiency). To do so, instead of energy intake, we used protein intake in our feeding efficiency calculation.

\section{Dominance hierarchy}

We established a female dominance hierarchy based on focal and ad libitum data of clearly submissive (bare teeth, give ground, make room) behaviors during decided agonistic interactions, i.e., spontaneous submission or aggression followed by submission by only one individual (Ostner et al. 2008). Ranks of all adult females were calculated as the standardized normalized David's score using the "DS" function of the "EloRating" package (Neumann et al. 2011) in R (versions 3.5.3; R Core Team 2020).

\section{Phenology}

At the middle of each month, ecological data were collected through phenology records on 45 botanical plots (32 plots of $50 \times 50 \mathrm{~m}$ and 13 of $100 \times 100 \mathrm{~m}$ ), covering a total area of 21 ha of forest. We monitored 673 trees $(\geq 10 \mathrm{~cm}$ diameter at breast height (DBH)), shrubs, and climbers ( $\geq 5 \mathrm{~cm} \mathrm{DBH})$ of 55 different fruit species, including $94 \%$ of the 35 important fruit items we had energy data on. Abundance of fruits (unripe, ripe, and old) was visually recorded using binoculars and scored on a logarithmic scale $(1=1-9 ; 2=10-99$; $3=100-999 ; 4=1000-9999 ; 5=10,000-99,999 ;$ Janson and Chapman 2000). Moreover, for each fruit species, density per hectare was calculated (based on all botanical plots). From the abundance and density data, we calculated a fruit availability index (FrAI) for each calendar month, using the following formula: 
$\operatorname{FrAI}_{m}=\sum_{i}^{n}\left(A_{i} \times D_{i}\right)$

where $F r A I_{\mathrm{m}}$ is the total fruit availability index of the month $m$ for $n$ fruit species, $A_{i}$ the mean fruit abundance score for species $i$, and $D_{i}$ the mean density of species $i$.

Using the $\operatorname{FrAI} I_{m}$ from two consecutive months, we were able to estimate a daily increase or decrease in FrAI between those 2 months. Thus, we assigned a fruit availability index for each day between the middle of two consecutive months with the following calculation:

$F r A I_{d}^{x}=F r A I_{m}+\left(x \times \frac{F r A I_{m+1}-F r A I_{m}}{n}\right)$,

where $F r A I_{d}^{x}$ is the daily FrAI of the $\mathrm{x}^{\text {th }}$ day between months $\mathrm{m}$ and $\mathrm{m}+1, F r A I_{m}$ is the FrAI of month $\mathrm{m}$, $F r A I_{m+1}$ is the FrAI of month $\mathrm{m}+1$ and $\mathrm{n}$ the total number of days between month $\mathrm{m}$ and $\mathrm{m}+1$ (i.e., $n=28,30$, or 31).

As previously done in Heesen et al. (2013), we only based this index on fruit items, as Assamese macaques are mainly frugivorous (Schülke et al. 2011; Heesen et al. 2013) and we expected fruit items to have a prevailing role in a female's diet and energy balance. We attributed an individual FrAI for each female within a sampling block by averaging the $\operatorname{Fr} A I_{d}$ from the days during which this female had been observed within the sampling block (i.e., days for which we have feeding data for this female).

\section{Travel distance}

We recorded GPS data at the beginning and at the end of each 40-min focal sampling session and at the sleeping trees (GPS device: Garmin GPSMAP 64 s). We calculated the shortest distance between two consecutive GPS records to assess the distance the group traveled on a given day. In a few cases $(N=36 / 363)$ where sleeping tree information was missing and/or less than five GPS coordinates were recorded during a day, the subsequent travel distance calculation was considered not reliable and no travel distance value was attributed to the respective day. For each sampling block, we attributed to each female the mean of the group travel distances during the days in which the respective female had been observed within the sampling block (i.e., days for which we have behavioral data for this female). On average, we used $25.8 \pm 0.3$ (average \pm SE) GPS coordinates to calculate the distance traveled by a group in 1 day (range: 12-50). Our estimation of daily travel distance was independent from the number of GPS points collected per day (linear regression: $t=1.76$, $N=283, P=0.08$ ).

\section{Urine sample collection}

We opportunistically collected urine samples throughout the day using disposable mini-pipettes. The first morning void was not caught. Urine contaminated by fecal matter was not collected as this could affect uCP measures (Higham et al. 2011a). We pipetted urine from clean disposable plastic bags placed underneath the urinating female or directly from vegetation. Urine was transferred into $2 \mathrm{~mL}$ Eppendorf vials and labelled with date, time of collection, and female ID. Right after urine collection, a few drops were pipetted on the lens of a handheld refractometer (Atago PAL-10S) to record specific gravity for adjusting uCP concentrations (see below), after which they were pipetted back into the vial. The vial was sealed with Parafilm and the refractometer lens was cleaned with Kimtech wipes. The urine samples were kept out of sunlight and cooled in a Thermos flask containing ice cubes until they were stored at $-12{ }^{\circ} \mathrm{C}$ in a camp freezer for a few days. They were later transported and placed into a bigger freezer $\left(-19^{\circ} \mathrm{C}\right)$ in a nearby village where they remained until export on dry ice to the endocrinology laboratory for hormone analysis.

\section{Urinary C-peptide analysis}

Frozen samples were thawed at room temperature and we assessed urinary C-peptide of insulin ( $\mathrm{UCP}$ ) via enzyme immunoassay using a commercial C-Peptide ELISA kit from IBL International GmbH Hamburg, Germany (RE 53,011 ), which has been validated and used successfully for uCP measurements in other macaques (Girard-Buttoz et al. 2011, 2014; Higham et al. 2011a, b), as well as baboons (Fürtbauer et al. 2020).

Prior to analysis, urine samples were diluted 1:2 to 1:20 (depending on C-Peptide concentration and urine volume available) with IBL sample diluent (RE 53,017-20), to bring the concentration into the linear range of the standard curve $(0.2-16 \mathrm{ng} / \mathrm{mL})$. In few cases, pure urine was used $(1: 1)$. Serial dilutions of urine samples resulted in displacement curves running parallel to the uCP standard curve, indicating no matrix interference. Assay sensitivity was $0.064 \mathrm{ng} / \mathrm{mL}$ and this threshold value was assigned to samples for which the uCP level was below assay sensitivity, as done in several uCP studies (Deschner et al. 2008; Girard-Buttoz et al. 2011; Higham et al. 2011a).

The inter-assay coefficient of variation (CV) calculated from high and low value quality controls assessed in each plate was $11.1 \%$ and $15.3 \%$, respectively $(N=68)$. Intraassay coefficient of variation, calculated as the average value from the individual CVs for all the sample duplicates, was below $10 \%$. To adjust for urinary concentration, we corrected uCP levels by the specific gravity (SG) of each sample (Miller et al. 2004; Anestis et al. 2009) and 
reported all corrected (corr.) uCP values in $\mathrm{ng} / \mathrm{mL}$ corr. SG. Highly diluted samples (SG below $1.002 ; N=27$ ) were discarded as correction with very low SG values might overestimate uCP concentrations. In total, the uCP concentration from 905 urine samples was used in this study, corresponding to an average of $2.2 \pm 0.05$ (average $\pm \mathrm{SE}$ ) urine samples per female and per sampling block.

\section{Data analysis}

\section{Activity budget (model 1) and diet composition (model 2)}

In order to investigate whether female reproductive state (5 different states) influenced the female's activity budget and/or diet composition, we fitted two linear mixed models (LMM; i.e., with Gaussian error distribution; Baayen et al. 2008) in R (versions 3.5.3 to 4.0.3; R Core Team 2020) using the function "Imer" (versions 1.2-21 to 1.1-25) of the package "Ime4" (Bates et al. 2015) and "Imer" (for testing individual effects) of the package "ImerTest" (version 3.1-3; Kuznetsova et al. 2017). Proportions of time allocated to each activity ( 4 categories: feeding, traveling, resting, social) as well as proportions of plant food items in the diet (5 categories: fruits, seeds, young leaves, animal matter, others) were calculated. To do so, for each female and within each sampling block, we (i) divided the number of instantaneous points recorded for each of the four activities by the total number of instantaneous points recorded, and (ii) divided the number of instantaneous points at which the female was feeding on each of the five respective categories of food items by the total number of feeding points. When a female's activity was unknown or when a female was feeding on an unknown food item, these observations were discarded, and therefore subtracted from the total number of instantaneous or feeding observations, respectively.

All proportions calculated to describe a female's activity budget or to describe her diet in a sampling block are not independent as they sum up to one. Therefore, the activity budget and diet composition data were respectively modelled all at once, using two compositional models. In addition, proportions range between zero and one. To account for this particular nature of the response variables, we transformed both response variables using a centered log-ratio (CLR), which is the log of the ratio between the observed proportions and their geometric mean per observation period and which removes the range restriction (Xia et al. 2018). To account for the zeros in the dataset, and therefore the impossibility to implement the CLR transformation in these cases, we first rescaled our proportions using the following formula, recommended for models to be fitted using a beta error distribution: $x^{\prime}=\frac{x \times(\text { length }(x)-1)+0.5}{\operatorname{length}(x)}$,

where $x$ is the observed proportion and length $(x)$ our sample size ( $N=1612$ or 2015 for activity budget or diet composition analysis respectively; Smithson and Verkuilen 2006).

We used the CLR-transformed proportions accounting for activity budget (model 1) and diet composition (model 2) as compositional response variables in our two LMMs. We included as fixed effects activity (4 categories, in model 1 ), or food item (5 categories, in model 2), and its respective two-way interaction with reproductive state, which accounted for our main hypothesis, namely, that female activity budget and diet composition vary with reproductive state. In addition to group, we controlled for the potential effects of FrAI and travel distance (to account for fruit abundance and physical expense, respectively) in explaining female activity budget and diet composition by including their two-way interactions with activity (model 1) and food item (model 2). We included two random intercepts in both LMMs: female ID and female ID nested in sampling block, with the latter accounting for the non-independence of the proportions within each sampling block. In order to avoid overconfident models, reproductive state and activity, or food item, were dummy coded and centered to be added as random slopes within female ID with activity, or food item, interacting with FrAI and with travel distance (Schielzeth and Forstmeier 2009; Barr 2013). We weighted the two models with the total number of instantaneous points (model 1) or feeding points (model 2) to account for a likely link between responses accuracy and sampling size.

The samples analyzed comprised a total of 1612 or 2015 transformed proportions on activity budget and diet composition, respectively, obtained for 43 adult females during 9 or 10 sampling blocks, depending on the group (403 observations comprising 4 or 5 proportions each).

\section{Cheek pouch use (model 3)}

We tested whether females in different reproductive states differed in their cheek pouch use. To do so, we fitted a model with a beta error distribution (Bolker 2008) and logit link function (McCullagh and Nelder 1989) with the function "glmmTMB" of the package "glmmTMB" (version 1.0.2.1; Brooks et al. 2017). The response variable was the proportion of time spent using cheek pouches per female and per sampling block ( $N=403$ observations). Proportion of time using cheek pouches was calculated by dividing the number of observations where the focal female was feeding from her cheek pouches by the total number of observations within a sampling block for the respective focal female. To avoid proportions being exactly zero, we rescaled our proportions using the same formula as described above. 
Reproductive state was the predictor variable. Additionally, we included as control variables FrAI, travel distance, group, and female dominance rank (which was found to predict female cheek pouch use in a previous study in this population; Heesen et al. 2014). Female dominance hierarchy was not included in any other models, as female activity budget and energy intake were found to be independent from it in this population (Heesen et al. 2013). Female ID was added as a random intercept effect, and within it, we included random slopes of reproductive state (dummy coded and centered), FrAI, and travel distance. The number of instantaneous points from which the response was calculated was further included as a weight to account for a potential link between response reliability and sampling size.

\section{Energy intake, protein intake, and feeding efficiency (models 4 to 7 )}

To test whether females' energy intake, protein intake, and feeding efficiency differed between reproductive states, we fitted four LMMs. The four responses were energy intake, protein intake, energetic feeding efficiency, and protein feeding efficiency (models 4, 5, 6, and 7 respectively). Reproductive state was the fixed effect predictor variable while FrAI, travel distance, and group were added as additional fixed effects to control for their potential influence. Female ID was included as a random intercept effect. FrAI and travel distance were added as random slopes within focal individual. We further weighted the models with the number of feeding points from which the four responses were calculated.

Some energy calculations could not be considered reliable enough (not representing at least $60 \%$ of a female's feeding observations within one sampling block), and were therefore discarded. Consequently, our sample size for these models was smaller than the previous ones $(N=177$ instead of $403, N=43$ females).

\section{uCP levels (model 8)}

We fitted an additional LMM to investigate how reproductive state affected female uCP levels. The response variable was uCP level in each urine sample $(N=905)$. The reproductive state of the female was our predictor variable and we added $\operatorname{Fr} A I_{d}$, daily travel distance, and group as fixed effects. Moreover, as in several primate species uCP have been found to be dependent on time of day (chimpanzees (Pan troglodytes): Georgiev 2012; gorillas (Gorilla beringei beringei): Grueter et al. 2014; blue monkeys (Cercopithecus mitis): Thompson et al. 2020), we added sampling time as an additional fixed effect in the model. Female ID was included as a random intercept effect, as was collection day, in order to account for multiple urine sampling per day. Reproductive state (dummy coded and centered), $F r A I_{d}$, daily travel distance, and time of day were included as random slopes within focal ID.

\section{Model assumptions and additional information}

Prior to fitting the models, we inspected quantitative predictors (FrAI and travel distance) to make sure their distributions were roughly symmetric. To achieve a more symmetric distribution, distance traveled was log-transformed (in models 3 to 8 ). The responses energy intake, protein intake, and feeding efficiency (energetic and protein) were log-transformed. In all models, we z-transformed FrAI and travel distance (as well as dominance hierarchy in model 3 and time of day in model 8) to make the models more likely to converge and easier to interpret (Schielzeth 2010). We also investigated potential under/overdispersion in the beta model (model 3). The dispersion parameter was 1.24, and therefore, the response was a little overdispersed which could be an issue in case a $p$ value would be just slightly below the 0.05 threshold.

After fitting the models, we visually inspected a QQ-plot of residuals and residuals plotted against fitted values to check whether the residuals were normally distributed and homogeneous (LMMs). These indicated no severe deviations from the assumptions. Using the function "vif" of the package "car" (Fox and Weisberg 2018), we checked for potential collinearity between predictor variables by inspecting the Variance Inflation Factors (VIF) derived from models lacking the random effects and interactions (maximum VIF across all models was 1.6, indicating no issues with collinearity). Furthermore, we assessed the models' stability by dropping the levels of the random intercepts one at a time (Nieuwenhuis et al. 2012) using a function provided by Roger Mundry; this procedure revealed the models to be of good stability. We bootstrapped models' estimates and confidence limits of model predictions using the functions "bootMer" of the package "lme4" or simulate of the package "glmmTMB", respectively.

To test the overall effect of reproductive state, and the interaction it was involved in on females' activity budget and diet composition, we compared the full models (as described above) with respective null models lacking reproductive state in the fixed effects part (Forstmeier and Schielzeth 2011). These comparisons were based on a likelihood ratio test (Dobson 2002). Apart from testing the general effect of reproductive state on our various responses, we also performed post hoc Tukey's pairwise comparison among each reproductive state from models 3 to 8 .

We tested the individual effects of each fixed effect using the function "drop1" from the package "Ime4." This function executes likelihood ratio tests comparing the full models with reduced ones lacking one fixed effect at a time. 


\section{Results}

\section{Activity budget (model 1)}

Overall, the null model was significantly different from the full model $\left(\chi^{2}=216.0, \mathrm{df}=16, P<0.001\right)$. The interaction between activity and reproductive state was significant $(F(12,827.5)=19.6, P<0.001)$, indicating that the activity budget of females differed between reproductive states. Plotting the results and inspecting fitted values together with their confidence intervals revealed that social time and traveling time were similar across reproductive states (Fig. 2; supplementary Table S1), while there was variation in feeding and resting time. Specifically, EL and NGNL females fed less and rested more than females in other reproductive states.

\section{Diet composition (model 2)}

The null model was significantly different from the full model $\left(\chi^{2}=278.4, \mathrm{df}=20, P<0.001\right)$. The interaction between food item category and reproductive state revealed a significant result $(F(16,893.9)=18.8, P<0.001)$, indicating that female diet composition differed between reproductive states. Plotting the results and inspecting the fitted values together with their confidence intervals revealed considerable variation with regards to the proportions of fruit and seeds in the diet (Fig. 3; supplementary Table S2). Specifically, EL and NGNL females fed more on fruits and less on seeds compared to females at other reproductive stages.

\section{Cheek pouch use (model 3)}

The full-null model comparison revealed a significant result and therefore, a significant effect of reproductive state on the frequency of cheek pouch use $\left(\chi^{2}=54.6\right.$, $\mathrm{df}=4, P<0.001$; Fig. 4 ; Table 1$)$. As the $p$ value is very small, we were confident that the significance can be trusted despite the slight overdispersion. Post hoc pairwise comparisons revealed that EG females used their cheek pouches the least. EG females used their cheek pouches less than LG $(t=-2.7, P=0.050)$, EL $(t=-8.6$, $P<0.001)$, LL $(t=-4.0, P=0.001)$, and NGNL females $(t=-3.3, P=0.009)$. Additionally, EL females used their cheek pouches more than LL females $(t=5.7, \mathrm{P}<0.001)$.

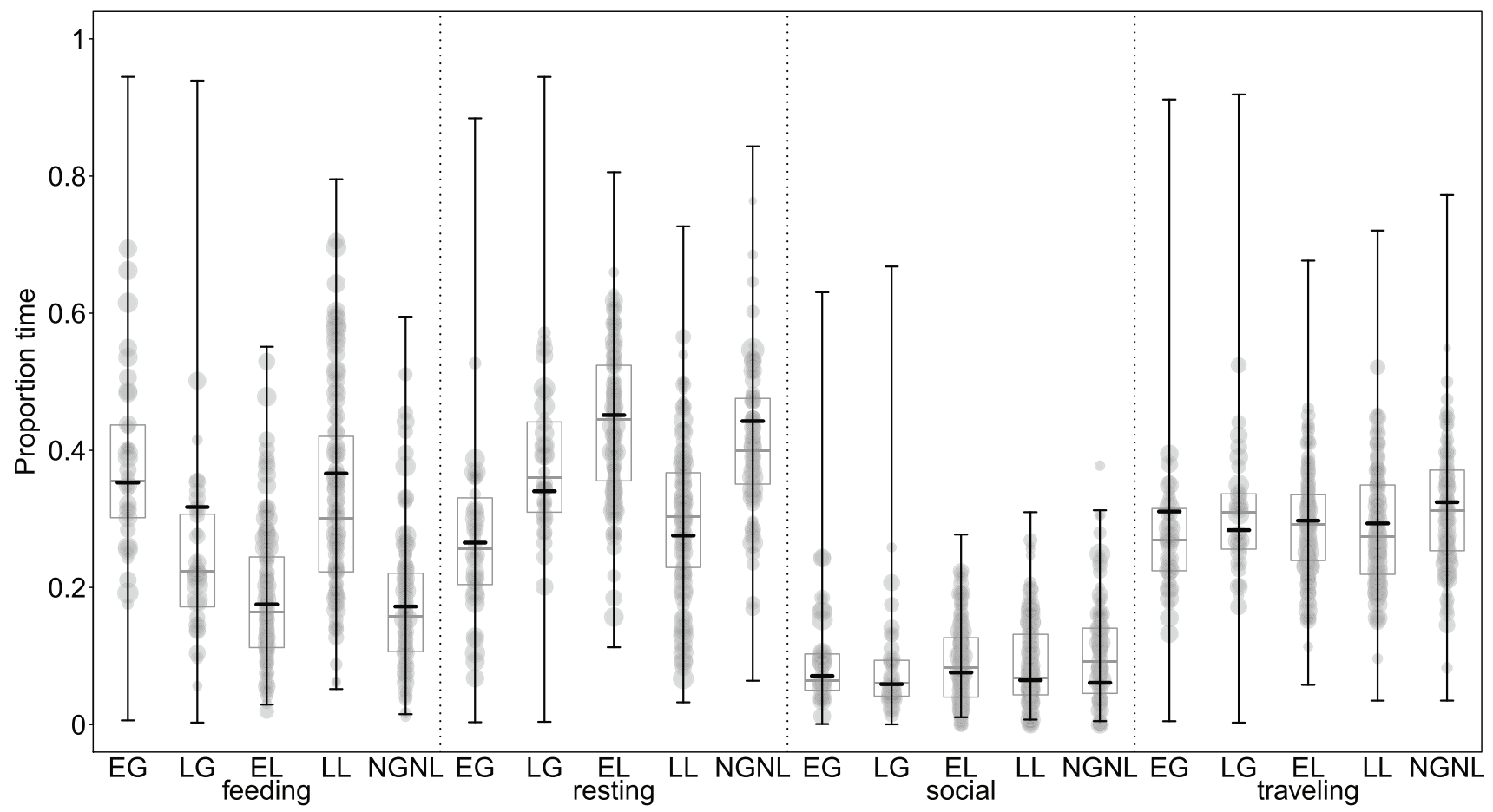

Fig. 2 Proportion of time spent feeding, resting, being social and traveling separately for female reproductive states (EG: early gestation; LG: late gestation; EL: early lactation; LL: late lactation; NGNL: non-gestating-non-lactating). The model's fitted values are represented by black thick horizontal lines and their respective confi- dence intervals are depicted as error bars. Grey boxes with thick horizontal lines depict medians and quartiles of the response. Grey dots represent data points and dot area indicates the weight of the data points in the model. $N=403$ data points in each activity, i.e., 1612 data points in total 


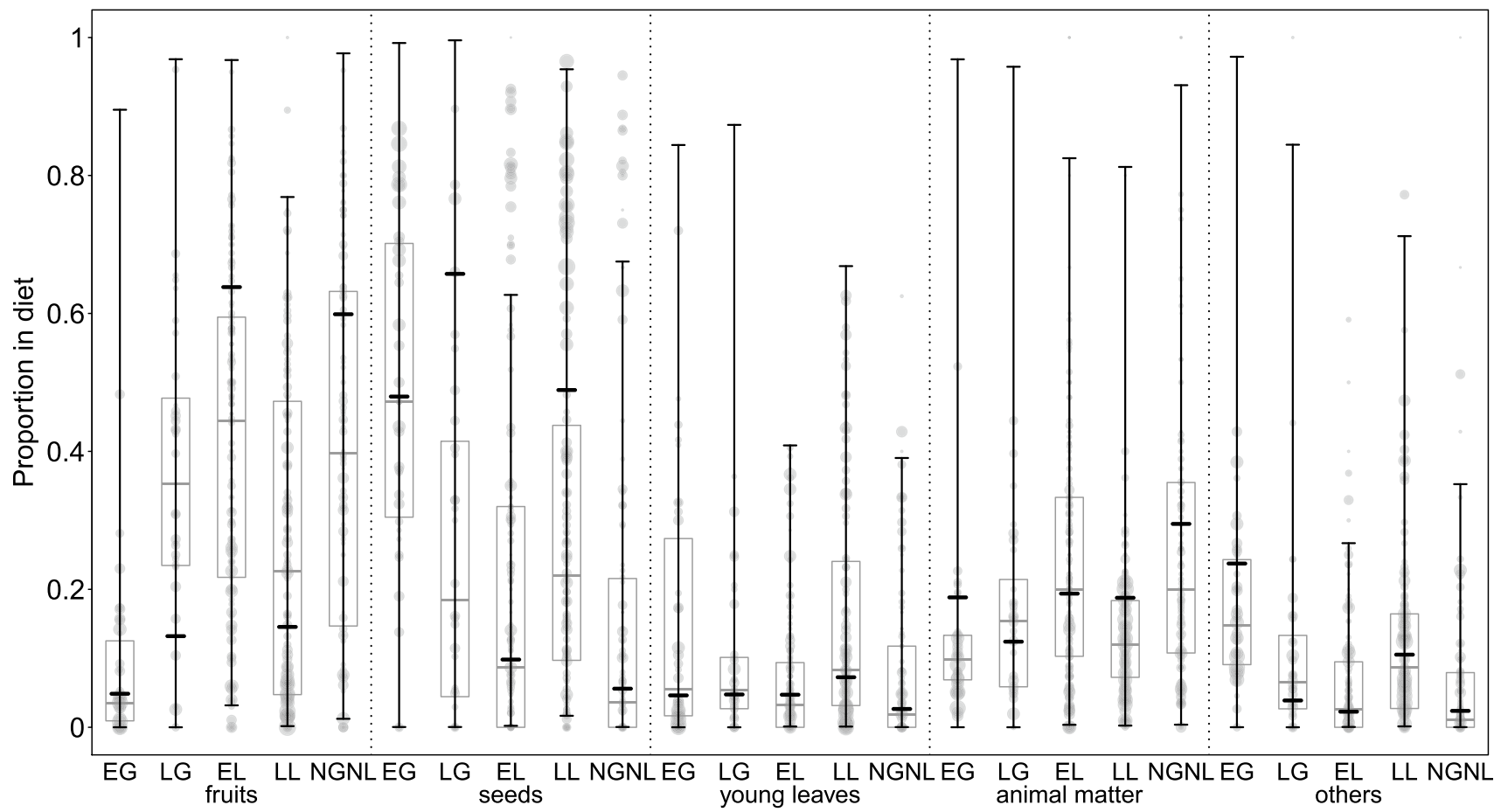

Fig. 3 Proportion of fruits, seeds, young leaves, animal matter, and other food items in female diet separately for female reproductive states (EG: early gestation; LG: late gestation; EL: early lactation; LL: late lactation; NGNL: non-gestating-non-lactating). Fitted values are represented by black thick horizontal lines and their respective confidence intervals by error bars. Grey boxes with thick horizontal lines depict medians and quartiles of the response. Grey dots represent data points and dot area indicates the weight of the data points in the model. $N=403$ data points in each food item category, i.e., 2015 data points in total
Fig. 4 Proportion of time spent using cheek pouches separately for female reproductive states (EG: early gestation; LG: late gestation; EL: early lactation; LL: late lactation; NGNL: non-gestating-non-lactating). Fitted values are represented with black thick horizontal lines and their respective confidence intervals with error bars. Black horizontal lines above the boxplot represent significant differences from the post hoc pairwise comparison. Grey boxes with thick horizontal lines depict medians and quartiles of the response. Grey dots represent data points and dot area indicates the weight of the data points in the model $(N=403)$

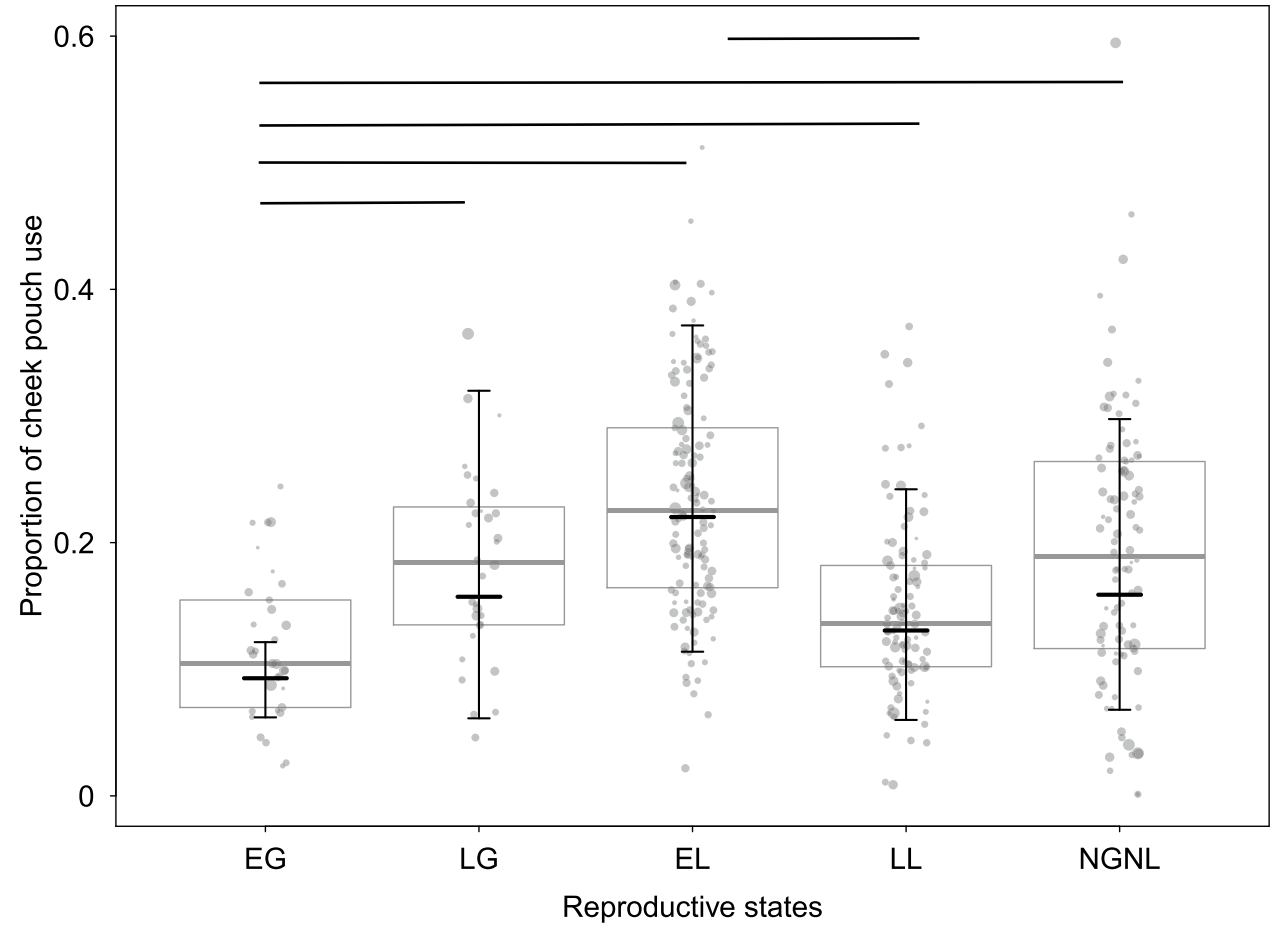


Table 1 Results of the beta model on cheek pouch use. This model tested the effect of reproductive state ( $E G$, early gestation; $L G$, late gestation; $E L$, early lactation; $L L$, late lactation; $N G N L$, non-gestating-non-lactating) on the proportion of time a female used her cheek pouches while controlling for the potential effects of FrAI, daily travel distance, dominance rank, and group. Female ID was added as a random intercept and each reproductive state was centered to be included with FrAI and daily travel distance as random slopes within female ID. The number of instantaneous points from which the response was calculated was further included as a weight. $N=43$ females, $N=403$ observations. Table shows model estimates, $S E$ standard errors, $C I$ confidence intervals, and $\min$ and max range of the estimates obtained when dropping one female from the random intercept one at a time (to assess model's stability)

\begin{tabular}{|c|c|c|c|c|c|c|c|c|c|}
\hline Term & Estimate & SE & Lower CI & Upper CI & $\min$ & $\max$ & $\chi^{2}$ & $\mathrm{df}$ & $P$ \\
\hline \multicolumn{10}{|l|}{ Model 3: cheek pouch use } \\
\hline (Intercept) & -2.235 & 0.126 & -2.690 & -1.903 & -2.301 & -2.144 & & & \\
\hline Reproductive state $^{\mathrm{a}}$ & & & & & & & 54.569 & 4 & $<0.001$ \\
\hline (LG) & 0.600 & 0.219 & 0.021 & 1.225 & 0.523 & 0.719 & & & \\
\hline (EL) & 1.014 & 0.118 & 0.655 & 1.452 & 0.909 & 1.060 & & & \\
\hline (LL) & 0.383 & 0.095 & 0.005 & 0.837 & 0.303 & 0.436 & & & \\
\hline (NGNL) & 0.612 & 0.185 & 0.159 & 1.116 & 0.517 & 0.729 & & & \\
\hline Fruit availability index ${ }^{\mathrm{b}}$ & -0.215 & 0.051 & -0.344 & -0.085 & -0.236 & -0.194 & 14.958 & 1 & $<0.001$ \\
\hline Daily travel distance ${ }^{c}$ & -0.125 & 0.050 & -0.253 & 0.002 & -0.140 & -0.103 & 5.850 & 1 & 0.016 \\
\hline Dominance rank ${ }^{\mathrm{d}}$ & 0.021 & 0.069 & -0.141 & 0.191 & -0.003 & 0.058 & 0.093 & 1 & 0.760 \\
\hline Group $^{\mathrm{e}}$ & & & & & & & 0.416 & 2 & 0.812 \\
\hline (MST) & -0.051 & 0.134 & -0.361 & 0.266 & -0.110 & -0.007 & & & \\
\hline$(\mathrm{SST})$ & -0.100 & 0.163 & -0.517 & 0.289 & -0.165 & -0.029 & & & \\
\hline
\end{tabular}

a'Dummy coded, with "EG" being the reference category; the indicated test refers to the overall effect of reproductive state

${ }^{b} \mathrm{z}$-transformed; mean and standard error of the original variable were 36.131 and 0.679 , respectively

${ }^{c} \log$ - and z-transformed; mean and standard error of the original variable were 1755.073 and 15.091, respectively (in meters)

${ }^{\mathrm{d}} \mathrm{z}$-transformed; mean and standard error of the original variable were 7.719 and 0.157 , respectively

'Dummy coded, with group "MOT" being the reference category

\section{Energy intake (model 4)}

Null and full models differed significantly from each other, suggesting that reproductive state had a significant effect on a female's energy intake $\left(\chi^{2}=23.2, \mathrm{df}=4, P<0.001\right.$; Fig. 5a; Table 2a). Energy intake in EL and NGNL females was higher than in EG females $(z=4.5, P<0.001$ and $z=3.6$, $P=0.003$, respectively). Additionally, energy intake in EL females was higher than in LL females $(z=3.1, P=0.02)$.

\section{Protein intake (model 5)}

The full-null model comparison did not reveal a significant result $\left(\chi^{2}=4.0, \mathrm{df}=4, P=0.402\right)$. Therefore, reproductive state had no obvious effect on a female's protein intake (Fig. 5b).

\section{Energetic feeding efficiency (model 6)}

The null model was significantly different from the full model, revealing that reproductive state had a significant effect on a female's energetic feeding efficiency $\left(\chi^{2}=56.4\right.$, $\mathrm{df}=4, P<0.001$; Fig. $5 \mathrm{c}$; Table 2b). Energetic feeding efficiency in EL and NGNL females was higher than in EG $(z=6.0, P<0.001$ and $z=6.0, P<0.001$, respectively) and LL females $(z=5.7, P<0.001$ and $z=5.6, P<0.001$, respectively).

\section{Protein feeding efficiency (model 7)}

Null and full models differed significantly indicating that reproductive state had a significant effect on a female's protein feeding efficiency $\left(\chi^{2}=35.4, \mathrm{df}=4, P<0.001\right.$; Fig. 5d; Table 2c). Protein feeding efficiency in EL and NGNL females was higher than in EG $(z=4.7, P<0.001$ and $z=4.1, P<0.001$, respectively) and LL females $(z=4.6$, $P<0.001$ and $z=3.9, P<0.001$, respectively).

\section{uCP levels (model 8)}

The last model revealed a significant difference between the null and the full model, meaning that uCP levels significantly differed between reproductive states $\left(\chi^{2}=18.3\right.$, $\mathrm{df}=4, P=0.001$; Fig. 6; Table 3). Gestating females exhibited the highest uCP levels, with uCP levels in LG females being higher than in EL $(z=3.8, P=0.001)$, LL $(z=3.1$, $P=0.016)$, and NGNL females $(z=2.7, P=0.048)$. Additionally, there was a trend toward higher uCP levels in EG than in EL females $(z=2.7, P=0.055)$. 
(a)

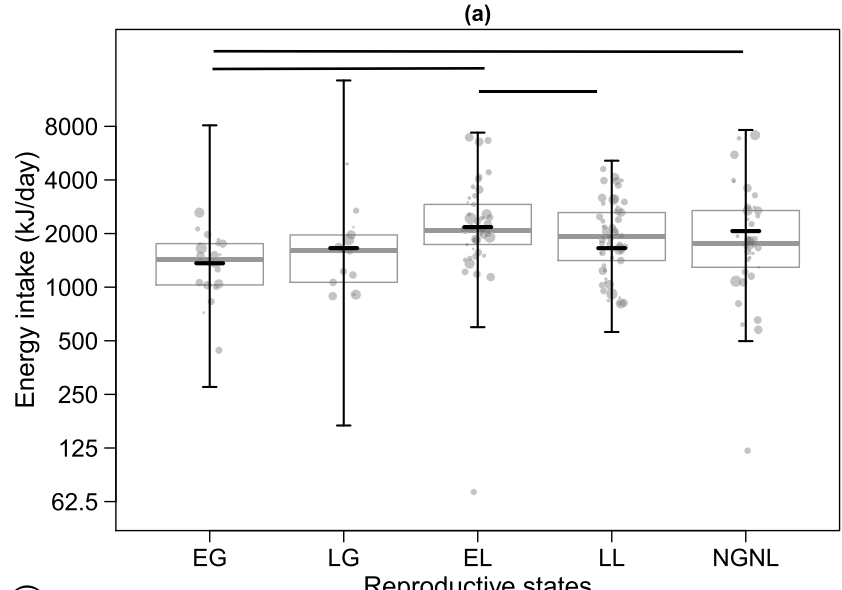

(c)

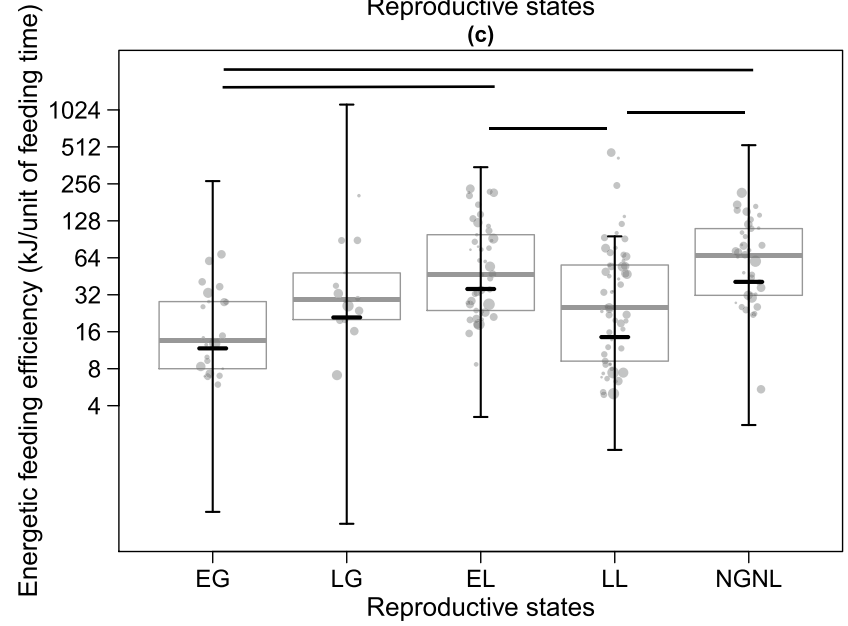

Fig. 5 a Energy intake, b protein intake, c energetic feeding efficiency, and $\mathbf{d}$ protein feeding efficiency separately for female reproductive states (EG: early gestation; LG: late gestation; EL: early lactation; LL: late lactation; NGNL: non-gestating-non-lactating). Fitted values are represented with black thick horizontal lines and their

\section{Discussion}

Species living in a seasonal habitat typically cope with the energetic costs of reproduction by timing their reproductive events with fluctuations of food abundance. In income breeders, females invest incoming energy in reproduction and synchronize lactation and peak of food abundance (Jönsson 1997). In capital breeders, females conceive after a peak of food abundance so that they store fat that will be metabolized during the reproductive cycle (Jönsson 1997). Relaxed income breeders, such as Assamese macaques, follow a mixed strategy consisting of fat accumulation before conception and a birth season timed around a peak of food availability (Brockman and van Schaik 2005; Heesen et al. 2013). Relatively, little is known regarding how this mixed breeding strategy translates into behavioral and physiological shifts during reproduction. We characterized these shifts by
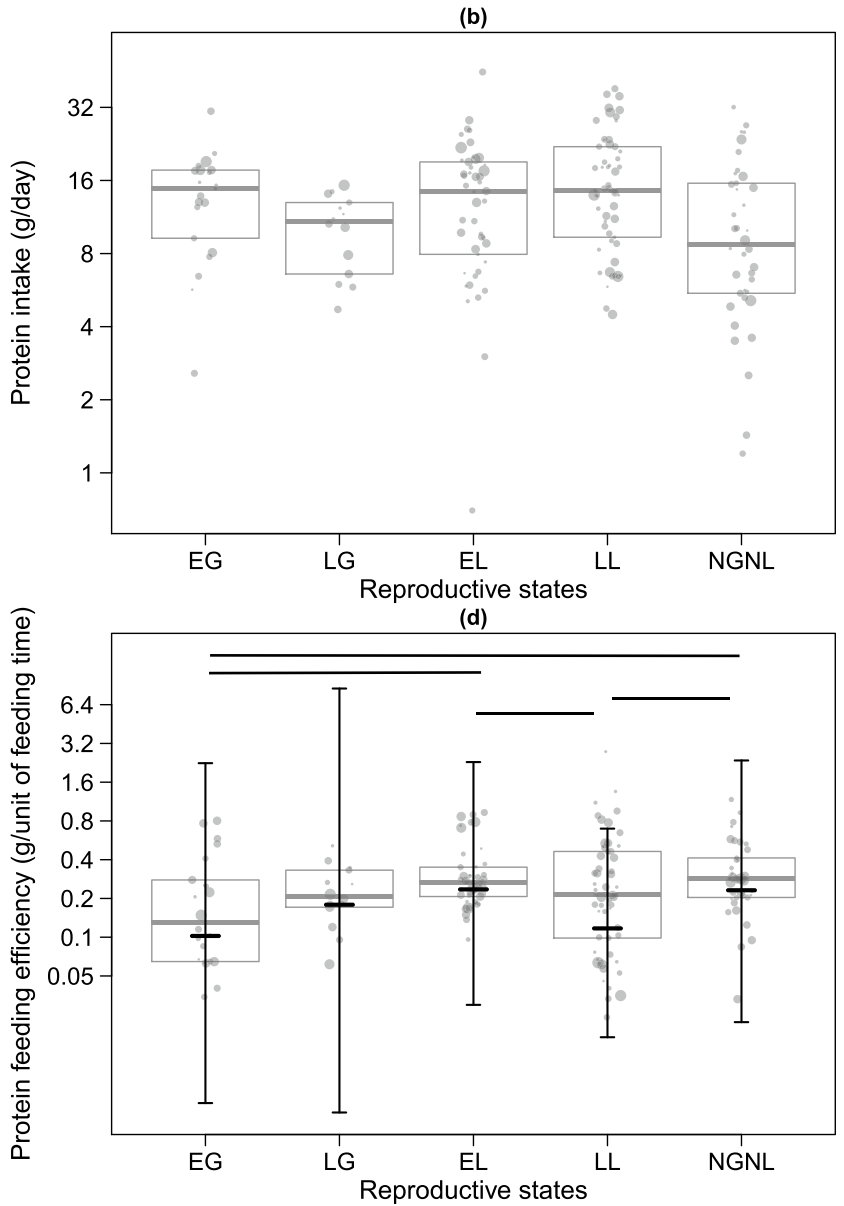

respective confidence intervals with error bars. Black horizontal lines above the boxplot represent significant differences from the post hoc pairwise comparison. Grey horizontal lines with boxes depict medians and quartiles of the response. Grey dots represent data points and dot area indicates the weight of the data points in the model $(N=177)$

investigating female behavior and physiology in Assamese macaques throughout the reproductive cycle. To do so, we used an integrative and multivariate approach, assessing female activity budget, diet composition, cheek pouch use, energy intake, protein intake, feeding efficiency, and urinary C-peptide (uCP). We compared these metrics both between and within gestation and lactation, using non-gestating-non-lactating (NGNL) females as a reference group.

\section{Gestation}

Gestating females behaved differently than NGNL females. First, and as predicted, gestating females exhibit different activity budgets than NGNL females. More specifically, they spent more time feeding and less time resting than NGNL females. In our study population, resource abundance prior to the mating season modulates the subsequent conception 
Table 2 Results of the (a) energy intake, (b) energetic feeding efficiency, and (c) protein feeding efficiency models. Each model tested the effect of reproductive state $(E G$, early gestation; $L G$, late gestation; $E L$, early lactation; $L L$, late lactation; $N G N L$, non-gestatingnon-lactating) on the respective response variable while controlling for the potential effects of FrAI, daily travel distance and group. In the four models, female ID was included as a random intercept. FrAI and daily travel distance were added as random slopes within female ID. The number of feeding points from which the response was calculated was further included as a weight in the four models. $N=43$ females, $N=177$ observations. Table shows model estimates, $S E$ standard errors, $C I$ confidence intervals, and min and max range of the estimates obtained when dropping one female from the random intercept one at a time (to assess models' stability)

\begin{tabular}{|c|c|c|c|c|c|c|c|c|c|}
\hline Term & Estimate & SE & Lower CI & Upper CI & $\min$ & $\max$ & $\chi^{2}$ & $\mathrm{df}$ & $P$ \\
\hline \multicolumn{10}{|l|}{ a) Model 4: energy intake } \\
\hline (Intercept) & 7.214 & 0.088 & 5.292 & 9.140 & 7.197 & 7.239 & & & \\
\hline Reproductive state $^{\mathrm{a}}$ & & & & & & & 23.189 & 4 & $<0.001$ \\
\hline (LG) & 0.196 & 0.171 & -2.693 & 2.981 & 0.134 & 0.298 & & & \\
\hline (EL) & 0.468 & 0.104 & -1.728 & 2.557 & 0.435 & 0.496 & & & \\
\hline (LL) & 0.195 & 0.091 & -1.988 & 2.364 & 0.164 & 0.222 & & & \\
\hline (NGNL) & 0.416 & 0.115 & -1.961 & 2.646 & 0.362 & 0.557 & & & \\
\hline Fruit availability index ${ }^{b}$ & 0.065 & 0.052 & -0.748 & 0.800 & 0.048 & 0.092 & 1.471 & 1 & 0.225 \\
\hline Daily travel distance ${ }^{c}$ & 0.041 & 0.064 & -0.900 & 1.021 & 0.011 & 0.070 & 0.348 & 1 & 0.555 \\
\hline Group $^{\mathrm{d}}$ & & & & & & & 0.004 & 2 & 0.998 \\
\hline (MST) & 0.004 & 0.075 & -1.408 & 1.420 & -0.026 & 0.029 & & & \\
\hline$(\mathrm{SST})$ & 0.005 & 0.139 & -2.119 & 2.190 & -0.095 & 0.048 & & & \\
\hline \multicolumn{10}{|c|}{ b) Model 6: Energetic feeding efficiency } \\
\hline (Intercept) & 2.419 & 0.159 & -1.247 & 5.736 & 2.354 & 2.475 & & & \\
\hline Reproductive state $^{\mathrm{a}}$ & & & & & & & 56.439 & 4 & $<0.001$ \\
\hline (LG) & 0.580 & 0.297 & -4.616 & 5.749 & 0.499 & 0.869 & & & \\
\hline (EL) & 1.113 & 0.187 & -2.846 & 4.964 & 1.058 & 1.187 & & & \\
\hline$(\mathrm{LL})$ & 0.212 & 0.164 & -3.401 & 4.026 & 0.161 & 0.254 & & & \\
\hline (NGNL) & 1.247 & 0.209 & -2.623 & 5.099 & 1.161 & 1.535 & & & \\
\hline Fruit availability index ${ }^{b}$ & -0.123 & 0.089 & -1.572 & 1.359 & -0.165 & -0.076 & 1.836 & 1 & 0.175 \\
\hline Daily travel distance ${ }^{c}$ & 0.036 & 0.117 & -1.663 & 1.641 & -0.018 & 0.082 & 0.080 & 1 & 0.778 \\
\hline Group $^{\mathrm{d}}$ & & & & & & & 2.351 & 2 & 0.309 \\
\hline (MST) & -0.034 & 0.134 & -2.506 & 2.439 & -0.105 & 0.006 & & & \\
\hline (SST) & 0.378 & 0.252 & -3.295 & 4.380 & 0.218 & 0.462 & & & \\
\hline \multicolumn{10}{|c|}{ c) Model 7: protein feeding efficiency } \\
\hline (Intercept) & -2.445 & 0.150 & -5.695 & 0.607 & -2.547 & -2.376 & & & \\
\hline Reproductive state $^{\mathrm{a}}$ & & & & & & & 35.445 & 4 & $<0.001$ \\
\hline (LG) & 0.559 & 0.277 & -4.142 & 5.477 & 0.492 & 0.826 & & & \\
\hline (EL) & 0.833 & 0.176 & -2.795 & 4.446 & 0.767 & 0.900 & & & \\
\hline (LL) & 0.135 & 0.154 & -3.464 & 3.497 & 0.077 & 0.210 & & & \\
\hline (NGNL) & 0.818 & 0.197 & -3.312 & 4.843 & 0.725 & 0.993 & & & \\
\hline Fruit availability index ${ }^{b}$ & 0.141 & 0.083 & -1.230 & 1.577 & 0.103 & 0.186 & 2.752 & 1 & 0.097 \\
\hline Daily travel distance ${ }^{c}$ & 0.141 & 0.107 & -1.504 & 1.731 & 0.097 & 0.195 & 1.337 & 1 & 0.248 \\
\hline Group $^{\mathrm{d}}$ & & & & & & & 11.033 & 2 & 0.004 \\
\hline (MST) & 0.090 & 0.127 & -2.322 & 2.473 & 0.046 & 0.144 & & & \\
\hline$(\mathrm{SST})$ & 0.798 & 0.234 & -2.724 & 4.272 & 0.693 & 0.902 & & & \\
\hline
\end{tabular}

a Dummy coded with "EG" being the reference category; the indicated test refers to the overall effect of reproductive state

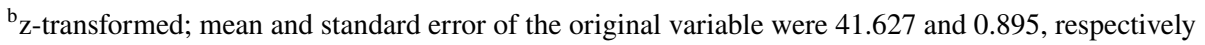

${ }^{c} \log$ - and z-transformed; mean and standard error of the original variable were 1656.021 and 21.436 , respectively (in meters)

${ }^{\mathrm{d}}$ Dummy coded, with group "MOT" being the reference category

rate (Heesen et al. 2013), in line with the pattern of female primates that exhibit better physical condition (more fat reserves) being more likely to conceive than females in worse physical condition (McFarland 1996; Ziegler et al. 2000). Additionally, being relaxed-income breeders, female Assamese macaques barely accumulate fat during gestation 
Fig. 6 Urinary C-peptide levels separately for female reproductive states (EG: early gestation; LG: late gestation; EL: early lactation; LL: late lactation; NGNL: non-gestating - nonlactating). Fitted values are represented with black thick horizontal lines and their respective confidence intervals with error bars. Black horizontal lines above the boxplot represent significant differences from the post hoc pairwise comparison (or a trend in the case of EG-EL comparison). Grey horizontal lines with boxes depict medians and quartiles of the response. Grey dots represent data points ( $N=905$ samples)

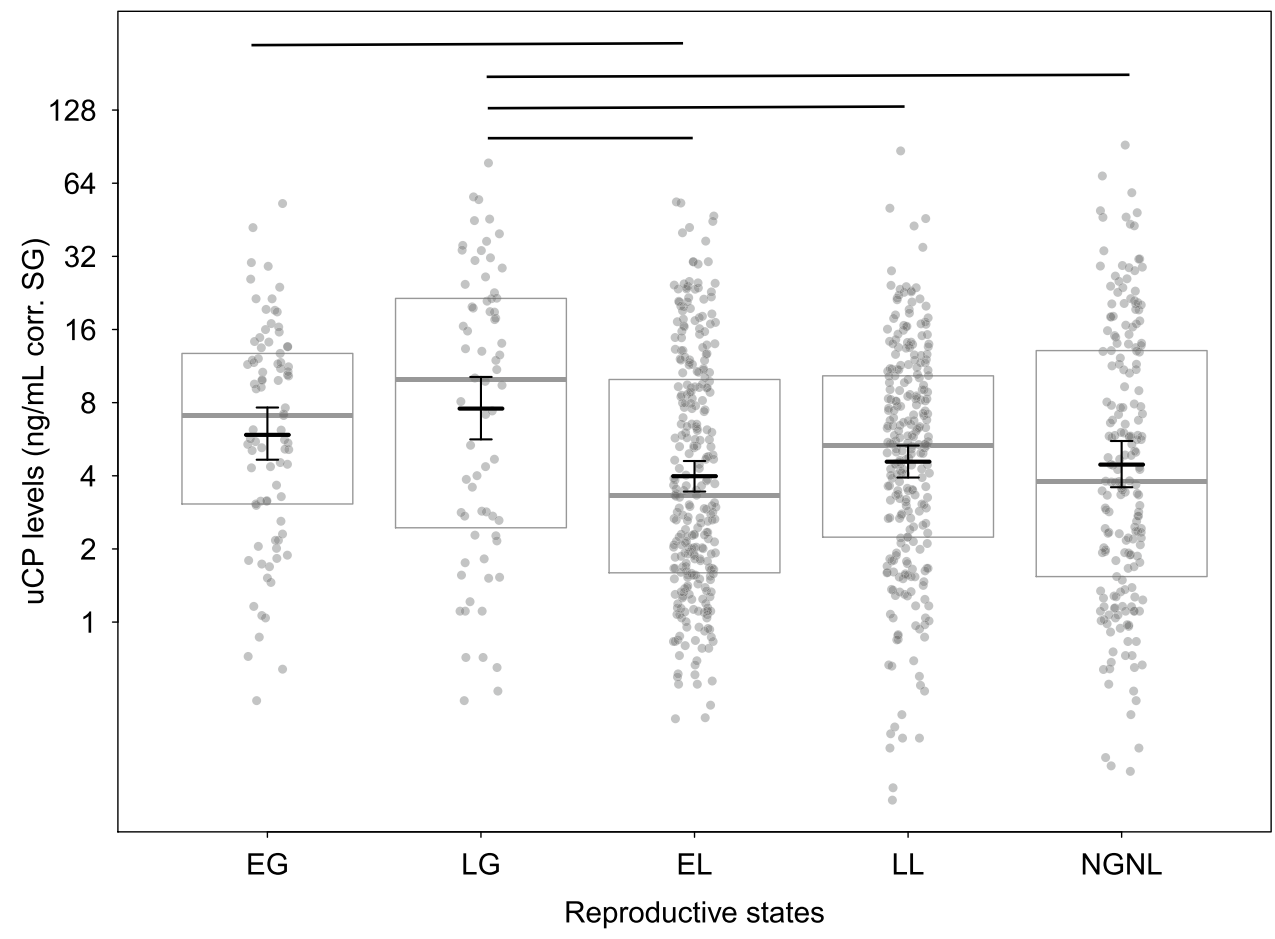

Table 3 Results of the uCP model. This model tested the effect of reproductive state ( $E G$, early gestation; $L G$, late gestation; $E L$, early lactation; $L L$, late lactation; $N G N L$, non-gestating-non-lactating) on uCP levels while controlling for the potential effects of $F r A I_{d}$, daily travel distance, time of day and group. Female ID and date were added as random intercepts. Each reproductive state was centered to be included with $F r A I_{d}$, daily travel distance, and time of day as random slopes within female ID. $N=43$ females, $N=905$ urine samples. Table shows model estimates, $S E$ standard errors, $C I$ confidence intervals, and min and max range of the estimates obtained when dropping levels of the random intercepts one at a time (to assess model's stability)

\begin{tabular}{|c|c|c|c|c|c|c|c|c|c|}
\hline Term & Estimate & SE & Lower CI & Upper CI & $\min$ & $\max$ & $\chi^{2}$ & df & $P$ \\
\hline \multicolumn{10}{|l|}{ Model 8: $u C P$} \\
\hline (Intercept) & 1.765 & 0.147 & 1.444 & 2.043 & 1.698 & 1.842 & & & \\
\hline Reproductive state $^{\mathrm{a}}$ & & & & & & & 18.34 & 4 & 0.001 \\
\hline (LG) & 0.249 & 0.201 & -0.160 & 0.650 & 0.184 & 0.310 & & & \\
\hline (EL) & -0.392 & 0.147 & -0.680 & -0.107 & -0.452 & -0.354 & & & \\
\hline (LL) & -0.255 & 0.145 & -0.532 & 0.037 & -0.312 & -0.214 & & & \\
\hline (NGNL) & -0.282 & 0.176 & -0.638 & 0.090 & -0.353 & -0.227 & & & \\
\hline Fruit availability index ${ }^{b}$ & 0.002 & 0.051 & -0.099 & 0.095 & -0.015 & 0.018 & 0.002 & 1 & 0.968 \\
\hline Daily travel distance ${ }^{c}$ & 0.012 & 0.050 & -0.087 & 0.117 & -0.006 & 0.026 & 0.053 & 1 & 0.818 \\
\hline Time of day ${ }^{b}$ & 0.133 & 0.051 & 0.023 & 0.235 & 0.114 & 0.150 & 6.335 & 2 & 0.012 \\
\hline Group $^{\mathrm{d}}$ & & & & & & & 0.294 & 2 & 0.863 \\
\hline (MST) & 0.030 & 0.108 & -0.177 & 0.238 & 0.005 & 0.072 & & & \\
\hline (SST) & -0.038 & 0.139 & -0.284 & 0.240 & -0.101 & 0.037 & & & \\
\hline
\end{tabular}

aDummy coded, with "EG" being the reference category; the indicated test refers to the overall effect of reproductive state

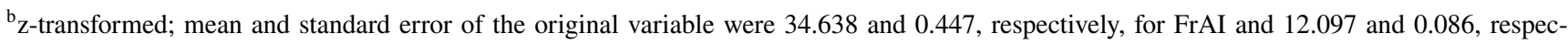
tively, for time of day (in h)

${ }^{c} \log$ - and z-transformed; mean and standard error of the original variable were 1771.061 and 15.491 , respectively (in meters)

${ }^{\mathrm{d}}$ Dummy coded, with group "MOT" being the reference category

(Brockman and van Schaik 2005), and therefore rely mostly on their pre-mating fat stores to support the energetic costs of gestation. Together, this suggests that gestating females, by feeding more at the expense of resting, do not follow an energy-conserving strategy, as their fat stores can be drawn upon to support the energy requirements of gestation. 
Second, and as expected, diet composition differed between gestating and NGNL females, but contrary to our prediction, gestating females consumed more seeds and less fruits than NGNL females. More generally, while fruits are richer in readily available energy (carbohydrates in the form of soluble sugar), seeds contain more protein and more fibers (Table S3; Fig. S1). Although not predicted specifically, fibers might be a valuable nutrient during gestation. Fibers refer to plant cell wall components, such as cellulose and hemicellulose, which need to be fermented in the gastrointestinal tract to provide energy. A fiber-rich diet during gestation increases female reproductive success through modulation of her gut microbiota composition, with consequences for the offspring's immune development (T cell maturation, antioxidant defense) and birth weight (mice (Mus musculus): Nakajima et al. 2017; humans: Hu et al. 2019; domestic pigs: Li et al. 2019; Weng 2019; Zhuo et al. 2020). Consuming more fibers during gestation may be selected in Assamese macaques for its beneficial effect on female reproductive performance.

Contrary to our predictions, gestating and NGNL females did not differ in the other investigated metrics. For example, gestating females did not consume more proteins than NGNL females, as there was no difference in young leaf consumption or in protein intake. Note that our protein intake calculation came exclusively from plant food items, as we could not account for the nutrient content of animal matter, and thus excluded a probably important source of protein (Bergstrom et al. 2019), which can represent up to $24 \%$ of feeding time, for example, in early lactating females of our study. We cannot discuss the proportion of animal matter in the diet, as we were unable to control for animal prey availability in the habitat.

Although gestating and NGNL females consumed the same quantity of (plant) protein, the proportion of protein in the diet may differ. We thus ran a post hoc model similar to the protein intake model (model 5), but with protein intake ratio as the response variable (dividing the quantity of protein intake by the total quantity of plant food item consumed in a day; Table S4; Fig. S2). The proportion of protein was indeed significantly higher in early gestating compared to NGNL females. Consequently, as the proportion of protein is higher in early gestating than in NGNL females, while the quantity of protein is the same among these two categories of females, early gestating females may consume a lower amount of food per day than NGNL females. Still, early gestating females manage to have similar protein intake as NGNL females, probably by consuming more seeds. The higher proportion of protein in the diet of early gestating females may have beneficial effects on the offspring (Langley-Evans et al. 1996).

Levels of uCP were the highest during gestation, especially in late gestation, in line with results in other primate species (bonobos (Pan paniscus): Nurmi et al. 2018; chacma baboons (Papio ursinus): Fürtbauer et al. 2020). Elevated uCP levels during gestation can reflect maternal insulin resistance induced by a shift in maternal energy metabolism from carbohydrate to lipid oxidation (Cianni et al. 2003). Consequently, we cannot reliably assess energy balance from $\mathrm{uCP}$ levels during gestation because of the maternal change in insulin sensitivity at this stage of the reproductive cycle. However, we can infer that insulin resistance and the associated metabolic shift in mothers' energy source allow a redirection of carbohydrates to support the fetus' needs (Butte 2000) and reflect a physiological adaptation prioritizing the energetic requirements of the fetus via the most readily available source of maternal energy.

Among gestating females, our results emphasize differences between early and late gestation. We found that only early (and not late) gestating females have lower energy intake and lower feeding efficiency than NGNL females. Although in contrast with our predictions, these results make sense in light of the results discussed above. Feeding mainly on seeds during gestation does not provide much energyrich carbohydrates and may yield a low energy intake and feeding efficiency. The fact that late gestating females were not significantly different from NGNL females in terms of energy intake and feeding efficiency may suggest a slight change in feeding behavior over the course of gestation. This is also consistent with late gestating female relying less on protein in their diet than early gestating females (Fig. S2) and using their cheek pouches more often. Storing more food items in their cheek pouches might contribute to a slightly better (although non-significant) feeding efficiency in the later stages of gestation. More data are needed to investigate further feeding behavior shifts during gestation.

\section{Lactation}

Unexpectedly, early lactation did not exhibit the strongest behavioral differences compared to NGNL females. To the contrary, early lactation was very similar to NGNL with regards to all metrics analyzed. Early lactating and NGNL females spent more time resting and less time feeding than females at other stages, indicative of an energy-conserving strategy in time of energetic constraints (Dasilva 1992; Rose 1994). More resting at the expense of feeding in early lactating females (Heesen et al. 2013) is potentially associated with several, non-exclusive benefits. Firstly, this energy-conserving strategy could be a way to offset the energy expenses induced by substantial suckling frequency in daytime during early lactation (Berghänel et al. 2016). As some maternal fat stores have been depleted during pregnancy (as reported in other species: Cothran et al. 1987; Lassek and Gaulin 2006), an energy-conserving strategy after parturition allows mothers to "save what is 
left" in order to allocate it to lactation. Secondly, while the mother is sitting and resting, the infant is in an upright position, which may increase its efficiency when suckling and digesting milk. Moreover, nursing a newborn might involve an additional activity such as vigilance, which is compatible with resting but not with feeding (Barrett et al. 2006; Dias et al. 2018). Lastly, while mothers in the study population typically rest together without grooming, the infants play nearby, which promotes their motor development (Berghänel et al. 2016; Ostner and Schülke 2018). Therefore, an energy-conserving strategy would have been selected for its contribution to increased female performance during the peak of lactation.

Surprisingly, NGNL females follow the same energyconserving strategy as early lactating females. It might be that NGNL females are not as free from energy requirements as we expected. NGNL females need to prepare for their next conceptions and thus, have to store as much fat as possible before the mating season to be able to reproduce (McFarland 1996; Brockman and van Schaik 2005; Heesen et al. 2013). The NGNL period may therefore be seen as setting the stage for subsequent reproduction, as fat accumulated during this period has an essential role to play in the subsequent reproductive states and thus, shapes female reproductive success.

Early lactating and NGNL females feed more on fruits than on seeds, and therefore seem to select items with higher carbohydrate content (Table S3; Fig. S1). Early lactating females are going through a substantial energy expense and carbohydrates provide a readily available source of energy, necessary to support maternal body function and maintenance. Fruit consumption probably is responsible for the high energy intake and feeding efficiency of early lactating and NGNL females. As these females cannot allocate as much time to feeding in order to rest and save energy to support lactation (EL females) or fat storage (NGNL females), when they feed they need to do it efficiently to optimize their time. Our results show that this is indeed the case as, similarly to other primate species, early lactating females exhibit a specific feeding strategy of increased energy intake and feeding efficiency, potentially helping them to compensate for the energetic costs of milk production (Kirkwood and Underwood 1984; Muruthi et al. 1991; Nievergelt and Martin 1999; McCabe and Fedigan 2007).

Contrary to our predictions, and as found in gestating females, lactating females had a protein intake similar to NGNL females. Here, our post hoc model with protein ratio as response becomes again useful to investigate whether these comparable quantities of protein ingested represent similar proportions in female diet. The results of the post hoc model showed that the proportion of protein was significantly higher in lactating females compared to NGNL females (Table S4; Fig. S2). Therefore, lactating females rely more on protein than NGNL females as this nutrient intake is likely associated with reproductive benefits (Kanakis et al. 2020).

uCP levels in early lactating females were unexpectedly similar to NGNL females (as found in Grueter et al. 2014; Cano-Huertes et al. 2017; Bergstrom et al. 2020; Fürtbauer et al. 2020), suggesting that females of these two reproductive stages - who have similar energy intake and a carbohydrate-rich diet-have similar energy balance, although early lactating females have substantial energy expenses. Some studies have shown that even under favorable nutritional conditions, uCP levels still decrease in situations of high energy expenditure requiring a rapid and immediate energy supply, such as in a period of infection or mating (Emery Thompson et al. 2009; Higham et al. 2011b). However, in our case, energy expenditure induced by early lactation is likely supported, at least in part, by lipid oxidation (maternal fat stores), alleviating the contribution of immediate energy intake. Additionally, the carbohydrate-rich diet of early lactating females is likely to induce high levels of uCP (Buyken et al. 2006). Together, fat oxidation and carbohydrate intake might compensate for the costs of early lactation, and participate in maintaining female uCP to similar levels as NGNL females (who store and save fat for later use).

Lastly, as predicted, early and late lactation patterns differed within lactating females, which reflects that the energetic costs of lactation are not static, but rather vary according to the infant growth rate (Lee 1987). Late lactating females were very similar to gestating females in not following an energy-conserving strategy. Potentially, as the infant becomes older and more autonomous during the day, it frees some time to the mother who can therefore allocate this extra time into feeding. Additionally, as females are in low physical condition when entering late lactation (Heesen et al. 2013), they might need to devote more time into feeding in order to regain body mass. Early lactating females also differ from late lactating ones in their cheek pouch use, with early lactating females using their cheek pouches more often than late lactating ones, probably because of their feeding time constraints. Moreover, when nursing a very young infant, early lactating females might try to avoid aggression induced by feeding competition on a food patch by filling up their cheek pouches and feeding in a safer place (Heesen et al. 2014). Therefore, in late lactation, females become relieved from some of the nursing load and allocate more time to feeding, as they do not have to rest as extensively anymore.

\section{Adaptive strategies or environmental effects?}

Across analyses, the most similar patterns occurred in females that had the strongest temporal overlap, i.e., earlylactating and NGNL on one side and gestating and late-lactating on the other side (Fig. 1). Importantly, all analyses 
controlled for variation in fruit availability, yet the nutritional quality of food may have changed over time and may account for the similar feeding behavior of females of different reproductive states co-occurring in the same months. Thus, females may either actively change their feeding behavior in response to their reproductive state, or may opportunistically consume what is available, resulting in comparable feeding patterns across females within month, irrespective of their reproductive state. We cannot completely discard the possibility that some periods of the year provide a nutrient access that is matching with specific nutrient requirements during the reproductive cycle, which may have led to the temporal timing of reproductive events in this population.

To further investigate this possible environmental effect, we plotted for each model and for each female the residuals against months and visually inspected them. If a temporal variation existed and had been missing in our models, then the residuals, i.e., the differences between the fitted and the observed values, would be very similar from one month to the next. None of the plots revealed such clustering of residuals through consecutive months, which indicates that there is no obvious monthly modulation in residuals, and thus, no important monthly parameters that we missed (Fig. S3). This suggests that our results are not explained by the temporal variation of a parameter (such as the nutritive quality of the month) that was not included in our models and thus, most likely reflect active changes of female feeding strategies. Our data show, however, large stochasticity, indicated by large confidence intervals. Therefore, some uncertainty still remains and further investigation is needed to fully confirm active, rather than passive, shifts in feeding behavior during the reproductive cycle.

Overall, Assamese macaque females coped with the variation in energetic costs of reproduction by actively or passively shifting behavioral patterns. They modified their activity budget, diet composition (leading to changes in energy intake and feeding efficiency), the use of cheek pouches, and sensitivity to insulin. Considering consequences of reproductive state both on female feeding behavior, assessed from different and complementary perspectives, and on female physiology, our study allowed us to address several questions simultaneously, and provided a comprehensive picture of the energetics of reproduction in a seasonal species with a mixed breeding strategy. Our results provide evidence that characteristics that are typical to strict income (no fat accumulation during gestation and high energy intake during lactation) and capital (fat accumulation before conception) breeders co-emerged in a species following a mixed breeding strategy. Further integrative studies will be helpful in determining whether different sets of such mixed characteristics are exhibited in other seasonal mammals that meet halfway on the spectrum of breeding strategies.
Supplementary Information The online version contains supplementary material available at https://doi.org/10.1007/s00265-021-03058-5.

Acknowledgements We are grateful to the National Research Council of Thailand (NRCT) and the Department of National Parks, Wildlife and Plant Conservation (DNP) for permission to carry out this research at the Phu Khieo Wildlife Sanctuary. We thank T. Wongsnak, C. Intumarn, W. Saenphala, A. Tadklang from Phu Khieo Wildlife Sanctuary for the support granted and N. Bhumpakphan for cooperation. We are grateful to A. Koenig and C. Borries, who established the field site. Special thanks go P. Saisawatdikul, T. Wisate, J. Wanart, K. Srithorn, S. Nurat, A. Boonsopin, and M. Swagemakers for their excellent help with urine sampling and behavioral data collection. We thank A. Heistermann for support in the endocrinology laboratory and R. Mundry for significant statistical help and for stimulating discussions. This study benefited from discussions in the research unit "Sociality and Health in Primates" (FOR 2136) and from valuable comments by C. GirardButtoz and an anonymous reviewer.

Funding Open Access funding enabled and organized by Projekt DEAL. This work was funded by the University of Goettingen and the German Primate Center, Germany.

Data availability The dataset generated and analyzed during the current study are available in the OSF repository, https://osf.io/jn8bc/?view_ only $=02 \mathrm{a} 091 \mathrm{c} 4 \mathrm{f} 50 \mathrm{a} 4425 \mathrm{be} 81483774177323$

Code availability Codes are available upon request.

\section{Declarations}

Ethics approval This study was conducted noninvasively and adhered to the ASAB/ABS Guidelines for the Use of Animals in Research (https://www.asab.org/ethics) and to the protocols approved by the Animal Welfare Body of the German Primate Center (Deutsches Primatenzentrum, DPZ) in Germany. Given the noninvasive nature of the study, no additional ethics approval was required. The Department of National Parks, Wildlife and Plant Conservation and the National Research Council of Thailand authorized data collection and export of samples with a benefit-sharing agreement (permit number: 0002/4137).

Consent to participate Not applicable.

Consent for publication Not applicable.

Competing interest The authors declare no competing interests.

Open Access This article is licensed under a Creative Commons Attribution 4.0 International License, which permits use, sharing, adaptation, distribution and reproduction in any medium or format, as long as you give appropriate credit to the original author(s) and the source, provide a link to the Creative Commons licence, and indicate if changes were made. The images or other third party material in this article are included in the article's Creative Commons licence, unless indicated otherwise in a credit line to the material. If material is not included in the article's Creative Commons licence and your intended use is not permitted by statutory regulation or exceeds the permitted use, you will need to obtain permission directly from the copyright holder. To view a copy of this licence, visit http://creativecommons.org/licenses/by/4.0/. 


\section{References}

Altmann J, Alberts S (2005) Growth rates in a wild primate population: ecological influences and maternal effects. Behav Ecol Sociobiol 57:490-501. https://doi.org/10.1007/s00265-004-0870-x

Anestis SF, Breakey AA, Beuerlein MM, Bribiescas RG (2009) Specific gravity as an alternative to creatinine for estimating urine concentration in captive and wild chimpanzee (Pan troglodytes) Samples. Am J Primatol 71:130-135. https://doi.org/10.1002/ ajp. 20631

Archie EA, Altmann J, Alberts SC (2014) Costs of reproduction in a long-lived female primate: injury risk and wound healing. Behav Ecol Sociobiol 68:1183-1193. https://doi.org/10.1007/ s00265-014-1729-4

Baayen H, Davidson D, Bates D (2008) Mixed-effects modeling with crossed random effects for subjects and items. J Mem Lang 59:390-412. https://doi.org/10.1016/j.jml.2007.12.005

Barr DJ (2013) Random effects structure for testing interactions in linear mixed-effects models. Front Psychol 4:328. https://doi. org/10.3389/fpsyg.2013.00328

Barrett L, Halliday J, Henzi P (2006) The ecology of motherhood: The structuring of lactation costs by chacma baboons. J Anim Ecol 75:875-886. https://doi.org/10.1111/j.1365-2656.2006. 01105.x

Bates D, Mächler M, Bolker B, Walker S (2015) Fitting linear mixedeffects models using lme4. J Stat Softw 67:1-48. https://doi.org/ 10.18637/jss.v067.i01

Bennett PM, Harvey PH (1985) Brain size, development and metabolism in birds and mammals. J Zool 207:491-509. https://doi.org/ 10.1111/j.1469-7998.1985.tb04946.x

Berghänel A, Heistermann M, Schülke O, Ostner J (2016) Prenatal stress effects in a wild, long-lived primate: predictive adaptive responses in an unpredictable environment. Proc R Soc B 283:20161304. https://doi.org/10.1098/rspb.2016.1304

Bergstrom ML, Hogan JD, Melin AD, Fedigan LM (2019) The nutritional importance of invertebrates to female Cebus capucinus imitator in a highly seasonal tropical dry forest. Am J Phys Anthropol 170:207-216. https://doi.org/10.1002/ajpa.23913

Bergstrom ML, Kalbitzer U, Campos FA, Melin AD, Emery Thompson M, Fedigan LM (2020) Non-invasive estimation of the costs of feeding competition in a neotropical primate. Horm Behav 118:104632. https://doi.org/10.1016/j.yhbeh.2019.104632

Bolker BM (2008) Ecological Models and Data in R. Princeton University Press, Princeton

Borries C, Larney E, Kreetiyutanonf K, Koenig A (2002) The diurnal primate community in a dry evergreen forest in Phu Khieo Wildlife Sanctuary, Northeast Thailand. Nat Hist Bull Siam Soc 50:75-88

Borries C, Lu A, Ossi-Lupo K, Larney E, Koenig A (2011) Primate life histories and dietary adaptations: a comparison of Asian colobines and Macaques. Am J Phys Anthropol 144:286-299. https://doi.org/10.1002/ajpa.21403

Brockman DK, van Schaik CP (2005) Seasonality and reproductive function. In: van Schaik CP, Brockman DK (eds) Seasonality in Primates: Studies of Living and Extinct Human and NonHuman Primates. Cambridge University Press, Cambridge, UK, pp. 269-306. https://doi.org/10.1017/CBO9780511542343.011

Brooks ME, Kristensen K, van Benthem KJ, Magnusson A, Berg CW, Nielsen A, Skaug HJ, Mächler M, Bolker BM (2017) glmmTMB balances speed and flexibility among packages for zero-inflated generalized linear mixed modeling. R J 9:378. https://doi.org/ 10.32614/RJ-2017-066

Butte NF (2000) Carbohydrate and lipid metabolism in pregnancy: normal compared with gestational diabetes mellitus. Am J Clin Nutr 71:1256S-1261S. https://doi.org/10.1093/ajcn/71.5.1256s
Buyken AE, Kellerhoff Y, Hahn S, Kroke A, Remer T (2006) Urinary C-peptide excretion in free-living healthy children is related to dietary carbohydrate intake but not to the dietary glycemic index. J Nutr 136:1828-1833. https://doi.org/10.1093/jn/136.7.1828

Buzzard P (2006) Cheek pouch use in relation to interspecific competition and predator risk for three guenon monkeys (Cercopithecus spp.). Primates J Primatol 47:336-341. https://doi.org/10.1007/ s10329-006-0188-6

Cano-Huertes B, Rangel-Negrín A, Coyohua-Fuentes A, ChaviraRamírez DR, Canales-Espinosa D, Dias PD (2017) Reproductive energetics of female mantled howlers (Alouatta palliata). Int J Primatol 38:942-961. https://doi.org/10.1007/ s10764-017-9990-9

Cianni GD, Miccoli R, Volpe L, Lencioni C, Prato SD (2003) Intermediate metabolism in normal pregnancy and in gestational diabetes. Diabetes Metab Res Rev 19:259-270. https://doi.org/ 10.1002/dmrr.390

Clutton-Brock TH, Albon SD, Guinness FE (1989) Fitness costs of gestation and lactation in wild mammals. Nature 337:260-262. https://doi.org/10.1038/337260a0

Clutton-Brock T, Iason G, Albon S, Guinness F (2009) Effects of lactation on feeding behaviour and habitat use in wild red deer hinds (Cervus elaphus). J Zool 198:227-236. https://doi.org/ 10.1111/j.1469-7998.1982.tb02072.x

Conklin-Brittain N, Knott C, Wrangham RW (2006) Energy intake by wild chimpanzees and orangutans: methodological considerations and a preliminary comparison. In: Hohmann G, Robbins MM, Boesch C (eds) Feeding Ecology in Apes and Other Primates: Ecological, Physical, and Behavioral Aspects. Cambridge University Press, Cambridge, UK, pp 445-471

Cooper MA, Chaitra MS, Singh M (2004) Effect of dominance, reproductive state, and group size on body mass in Macaca radiata. Int J Primatol 25:165-178. https://doi.org/10.1023/B: IJOP.0000014648.12402.b6

Cothran EG, Chesser RK, Smith MH, Johns PE (1987) Fat levels in female white-tailed deer during the breeding season and pregnancy. J Mammal 68:111-118. https://doi.org/10.2307/ 1381053

Dasilva GL (1992) The Western black-and-white colobus as a lowenergy strategist: activity budgets, energy expenditure and energy intake. J Anim Ecol 61:79-91. https://doi.org/10.2307/ 5511

Deschner T, Kratzsch J, Hohmann G (2008) Urinary C-peptide as a method for monitoring body mass changes in captive bonobos (Pan paniscus). Horm Behav 54:620-626. https://doi.org/10. 1016/j.yhbeh.2008.06.005

Dias P, Cano-Huertes B, Coyohua-Fuentes A, Chavira D, Canales D, Rangel-Negrín A (2018) Maternal condition and maternal investment during lactation in mantled howler monkeys. Am J Phys Anthropol 167:178-184. https://doi.org/10.1002/ajpa.23626

Dobson AJ (2002) An introduction to generalized linear models, 2nd edn. Chapman \& Hall/CRC, Boca Raton

Drent RH, Daan S (1980) The prudent parent: energetic adjustments in avian breeding. Ardea 55:225-252. https://doi.org/10.5253/ arde.v68.p225

Dufour DL, Sauther ML (2002) Comparative and evolutionary dimensions of the energetics of human pregnancy and lactation. Am J Hum Biol 14:584-602. https://doi.org/10.1002/ajhb.10071

Dunbar RIM, Dunbar P (1988) Maternal time budgets of gelada baboons. Anim Behav 36:970-980. https://doi.org/10.1016/ S0003-3472(88)80055-1

Durnin JVGA (1991) Energy requirements of pregnancy. Acta Paediatr 80:33-42. https://doi.org/10.1111/j.1651-2227.1991.tb18149.x

East M, Otto E, Helms J, Thierer D, Cable J, Hofer H (2015) Does lactation lead to resource allocation trade-offs in the spotted 
hyaena? Behav Ecol Sociobiol 69:805-814. https://doi.org/10. 1007/s00265-015-1897-x

Ellison PT, Valeggia CR (2003) C-peptide levels and the duration of lactational amenorrhea. Fertil Steril 80:1279-1280. https://doi. org/10.1016/S0015-0282(03)02158-7

Emery Thompson M, Knott C (2008) Urinary C-peptide of insulin as a non-invasive marker of energy balance in wild orangutans. Horm Behav 53:526-535. https://doi.org/10.1016/j.yhbeh.2007.12.005

Emery Thompson M, Muller MN, Wrangham RW (2012) The energetics of lactation and the return to fecundity in wild chimpanzees. Behav Ecol 23:1234-1241. https://doi.org/10.1093/beheco/ ars 107

Emery Thompson M, Muller MN, Wrangham RW, Lwanga JS, Potts KB (2009) Urinary C-peptide tracks seasonal and individual variation in energy balance in wild chimpanzees. Horm Behav 55:299-305. https://doi.org/10.1016/j.yhbeh.2008.11.005

Festa-Bianchet M (1989) Individual differences, parasites, and the costs of reproduction for bighorn ewes (Ovis canadensis). J Anim Ecol 58:785-795. https://doi.org/10.2307/5124

Festa-Bianchet M, Côté SD, Hamel S, Pelletier F (2019) Long-term studies of bighorn sheep and mountain goats reveal fitness costs of reproduction. J Anim Ecol 88:1118-1133. https://doi.org/10. 1111/1365-2656.13002

Festa-Bianchet M, Gaillard J-M, Jorgenson JT (1998) Mass- and density-dependent reproductive success and reproductive costs in a capital breeder. Am Nat 152:367-379. https://doi.org/10.2307/ 2463469

Forstmeier W, Schielzeth H (2011) Cryptic multiple hypotheses testing in linear models: overestimated effect sizes and the winner's curse. Behav Ecol Sociobiol 65:47-55. https://doi.org/10.1007/ s00265-010-1038-5

Fox J, Weisberg S (2018) An R companion to applied regression. SAGE Publications, Thousand Oakes, CA

Fürtbauer I, Christensen C, Bracken A, O'Riain MJ, Heistermann M, King AJ (2020) Energetics at the urban edge: Environmental and individual predictors of urinary C-peptide levels in wild chacma baboons (Papio ursinus). Horm Behav 126:104846. https://doi. org/10.1016/j.yhbeh.2020.104846

Fürtbauer I, Schülke O, Heistermann M, Ostner J (2010) Reproductive and life history parameters of wild female Macaca assamensis. Int J Primatol 31:501-517. https://doi.org/10.1007/ s10764-010-9409-3

Gamo Y, Bernard A, Mitchell SE, Hambly C, Jothery AA, Vaanholt LM, Król E, Speakman JR (2013) Limits to sustained energy intake. XVI. Body temperature and physical activity of female mice during pregnancy. J Exp Biol 216:2328-2338. https://doi. org/10.1242/jeb.078410

Georgiev A (2012) Energetic costs of reproductive effort in male chimpanzees, $\mathrm{PhD}$ dissertation, Harvard University

Girard-Buttoz C, Higham JP, Heistermann M, Wedegärtner S, Maestripieri D, Engelhardt A (2011) Urinary C-peptide measurement as a marker of nutritional status in macaques. PLoS ONE 6:e18042. https://doi.org/10.1371/journal.pone.0018042

Girard-Buttoz C, Heistermann M, Rahmi E, Marzec A, Agil M, Fauzan PA, Engelhardt A (2014) Mate-guarding constrains feeding activity but not energetic status of wild male long-tailed macaques (Macaca fascicularis). Behav Ecol Sociobiol 68:583-595. https://doi.org/10.1007/s00265-013-1673-8

Gittleman J, Thompson S (1988) Energy allocation in mammalian reproduction. Integr Comp Biol 28:863-875. https://doi.org/10. 1093/icb/28.3.863

Goldberg GR, Prentice AM, Coward WA, Davies HL, Murgatroyd PR, Sawyer MB, Ashford J, Black AE (1991) Longitudinal assessment of the components of energy balance in well-nourished lactating women. Am J Clin Nutr 54:788-798. https://doi.org/ 10.1093/ajcn/54.5.788
Gould L, Sussman RW, Sauther ML (2003) Demographic and life-history patterns in a population of ring-tailed lemurs (Lemur catta) at Beza Mahafaly Reserve, Madagascar: a 15-year perspective. Am J Phys Anthropol 120:182-194

Grueter CC, Deschner T, Behringer V, Fawcett K, Robbins MM (2014) Socioecological correlates of energy balance using urinary C-peptide measurements in wild female mountain gorillas. Physiol Behav 127:13-19. https://doi.org/10.1016/j.physbeh. 2014.01.009

Guillermo-Tuazon M, Barba C, van Raaij J, Hautvast JGAJ (1992) Energy intake, energy expenditure, and body composition of poor rural Philippine women throughout the first 6 mo of lactation. Am J Clin Nutr 56:874-880. https://doi.org/10.1093/ajcn/56.5. 874

Hall KD, Heymsfield SB, Kemnitz JW, Klein S, Schoeller DA, Speakman JR (2012) Energy balance and its components: implications for body weight regulation. Am J Clin Nutr 95:989-994. https:// doi.org/10.3945/ajen.112.036350

Harris T, Chapman C, Monfort S (2009) Small folivorous primate groups exhibit behavioral and physiological effects of food scarcity. Behav Ecol 21:46-56. https://doi.org/10.1093/beheco/ $\operatorname{arp} 150$

Hayes VJ, Henzi SP, Freedman L, Gaynor D (1992) The differential use of cheek pouches in a troop of Papio ursinus. Primates 33:477500. https://doi.org/10.1007/BF02381151

Heesen M, Rogahn S, Macdonald S, Ostner J, Schülke O (2014) Predictors of food-related aggression in wild Assamese macaques and the role of conflict avoidance. Behav Ecol Sociobiol 68:1829_ 1841. https://doi.org/10.1007/s00265-014-1792-x

Heesen M, Rogahn S, Ostner J, Schülke O (2013) Food abundance affects energy intake and reproduction in frugivorous female Assamese macaques. Behav Ecol Sociobiol 67:1053-1066. https://doi.org/10.1007/s00265-013-1530-9

Herrera E, Heymann E (2004) Does mom need more protein? Preliminary observations on differences in diet composition in a pair of red titi monkeys (Callicebus cupreus). Folia Primatol 75:150-153. https://doi.org/10.1159/000078304

Higham JP, Girard-Buttoz C, Engelhardt A, Heistermann M (2011) Urinary C-peptide of insulin as a non-invasive marker of nutritional status: some practicalities. PLoS ONE 6:e22398. https:// doi.org/10.1371/journal.pone.0022398

Higham JP, Heistermann M, Maestripieri D (2011b) The energetics of male-male endurance rivalry in free-ranging rhesus macaques, Macaca mulatta. Anim Behav 81:1001-1007. https://doi.org/10. 1016/j.anbehav.2011.02.001

Hinde K, Milligan LA (2011) Primate milk: Proximate mechanisms and ultimate perspectives. Evol Anthropol 20:9-23. https://doi. org/10.1002/evan.20289

Hu M, Eviston D, Hsu P et al (2019) Decreased maternal serum acetate and impaired fetal thymic and regulatory $\mathrm{T}$ cell development in preeclampsia. Nat Commun 10:3031. https://doi.org/10.1038/ s41467-019-10703-1

Janson CH, Chapman CA (2000) Primate resources and the determination of primate community structure. In: Fleagle JG, Janson $\mathrm{CH}$, Reed K (eds) Primate Communities. Cambridge University Press, Cambridge, UK, pp 237-267

Jönsson KI (1997) Capital and income breeding as alternative tactics of resource use in reproduction. Oikos 78:57-66. https://doi.org/ $10.2307 / 3545800$

Kanakis I, Alameddine M, Scalabrin M, van 't Hof RJ, Liloglou T, Ozanne SE, Goljanek-Whysall K, Vasilaki A (2020) Low protein intake compromises the recovery of lactation-induced bone loss in female mouse dams without affecting skeletal muscles. bioRxiv 2020.05.02.073759. https://doi.org/10.1101/2020.05. 02.073759 
Kirkwood JK, Underwood SJ (1984) Energy requirements of captive cotton-top tamarins (Saguinus oedipus oedipus). Folia Primatol 42:180-187. https://doi.org/10.1159/000156160

Knott CD (1998) Changes in orangutan caloric intake, energy balance, and ketones in response to fluctuating fruit availability. Int J Primatol 19:1061-1079. https://doi.org/10.1023/A:1020330404983

Koenig A, Borries C, Chalise M, Winkler P (1997) Ecology, nutrition, and timing of reproductive events in an Asian primate, the Hanuman langur (Presbytis entellus). J Zool 243:215-235. https://doi. org/10.1111/J.1469-7998.1997.TB02778.X

Koivula M, Koskela E, Mappes T, Oksanen TA (2003) Cost of reproduction in the wild: manipulation of reproductive effort in the bank vole. Ecology 84:398-405. https://doi.org/10.1890/00129658(2003)084[0398:CORITW]2.0.CO;2

Kuznetsova A, Brockhoff PB, Christensen RHB (2017) lmerTest package: tests in Linear Mixed Effects Models. J Stat Softw 82:1-26. https://doi.org/10.18637/jss.v082.i13

Lambert JE (2005) Competition, predation, and the evolutionary significance of the cercopithecine cheek pouch: The case of Cercopithecus and Lophocebus. Am J Phys Anthropol 126:183-192. https://doi.org/10.1002/ajpa.10440

Lambert JE, Rothman JM (2015) Fallback foods, optimal diets, and nutritional targets: primate responses to varying food availability and quality. Annu Rev Anthropol 44:493-512. https://doi.org/10. 1146/annurev-anthro-102313-025928

Langley-Evans SC, Welham SJM, Sherman RC, Jackson AA (1996) Weanling rats exposed to maternal low-protein diets during discrete periods of gestation exhibit differing severity of hypertension. Clin Sci 91:607-615. https://doi.org/10.1042/cs0910607

Lassek WD, Gaulin SJC (2006) Changes in body fat distribution in relation to parity in American women: A covert form of maternal depletion. Am J Phys Anthropol 131:295-302. https://doi.org/ 10.1002/ajpa.20394

Lee PC (1987) Nutrition, fertility and maternal investment in primates. J Zool 213:409-422. https://doi.org/10.1111/j.1469-7998.1987. tb03717.x

Lee PC, Majluf P, Gordon IJ (1991) Growth, weaning and maternal investment from a comparative perspective. J Zool 225:99-114. https://doi.org/10.1111/j.1469-7998.1991.tb03804.x

Li Y, Liu H, Zhang L, Yang Y, Lin Y, Zhuo Y, Fang Z, Che L, Feng B, Xu S, Li J, Wu D (2019) Maternal dietary fiber composition during gestation induces changes in offspring antioxidative capacity, inflammatory response, and gut microbiota in a sow model. Int $\mathbf{J}$ Mol Sci 21:31. https://doi.org/10.3390/ijms21010031

Logan M, Sanson G (2003) The effects of lactation on the feeding behaviour and activity patterns of free-ranging female koalas (Phascolarctos cinereus Goldfuss). Aust J Zool 51:415-428. https://doi.org/10.1071/ZO03017

Martin R (1996) Scaling of the mammalian brain: the maternal energy hypothesis. Physiology 11:149-156. https://doi.org/10.1152/ physiologyonline.1996.11.4.149

McCabe GM, Emery Thompson M (2013) Reproductive seasonality in wild Sanje mangabeys (Cercocebus sanjei), Tanzania: relationship between the capital breeding strategy and infant survival. Behaviour 150:1399-1429. https://doi.org/10.1163/1568539X00003102

McCabe GM, Fedigan LM (2007) Effects of reproductive status on energy intake, ingestion rates, and dietary composition of female Cebus capucinus at Santa Rosa, Costa Rica. Int J Primatol 2:837-851. https://doi.org/10.1007/s10764-007-9159-z

McCullagh P, Nelder JA (1989) Generalized Linear Models. Chapman \& Hall, London, UK

McFarland R (1996) Female primates: Fat or fit? In: Morbeck ME, Galloway A, Zihlman A (eds) The Evolving Female. Princeton University Press, Princeton, pp 163-176
Meistas MT, Rendell M, Margolis S, Kowarski AA (1982) Estimation of the secretion rate of insulin from the urinary excretion rate of C-peptide: study in obese and diabetic subjects. Diabetes 31:449-453. https://doi.org/10.2337/diab.31.5.449

Melani F, Rubenstein AH, Oyer PE, Steiner DF (1970) Identification of proinsulin and C-peptide in human serum by a specific immunoassay. P Natl Acad Sci USA 67:148-155. https://doi.org/10. 1073/pnas.67.1.148

Mellado M, Rodríguez A, Villarreal JA, Olvera A (2005) The effect of pregnancy and lactation on diet composition and dietary preference of goats in a desert rangeland. Small Rumin Res 58:79-85. https://doi.org/10.1016/j.smallrumres.2004.07.014

Miller KE, Bales KL, Ramos JH, Dietz JM (2006) Energy intake, energy expenditure, and reproductive costs of female wild golden lion tamarins (Leontopithecus rosalia). Am J Primatol 68:10371053. https://doi.org/10.1002/ajp.20306

Miller RC, Brindle E, Holman DJ, Shofer J, Klein NA, Soules MR, O'Connor KA (2004) Comparison of specific gravity and creatinine for normalizing urinary reproductive hormone concentrations. Clin Chem 50:924-932. https://doi.org/10.1373/clinc hem.2004.032292

Murray CM, Lonsdorf EV, Eberly LE, Pusey AE (2009) Reproductive energetics in free-living female chimpanzees (Pan troglodytes schweinfurthii). Behav Ecol 20:1211-1216. https://doi. org/10.1093/beheco/arp114

Muruthi P, Altmann J, Altmann S (1991) Resource base, parity, and reproductive condition affect females' feeding time and nutrient intake within and between groups of a baboon population. Oecologia 87:467-472. https://doi.org/10.1007/BF00320408

Nakajima A, Kaga N, Nakanishi Y et al (2017) Maternal high fiber diet during pregnancy and lactation influences regulatory $\mathrm{T}$ cell differentiation in offspring in mice. J Immunol 199:35163524. https://doi.org/10.4049/jimmunol.1700248

Neuhaus P (2000) Weight comparisons and litter size manipulation in Columbian ground squirrels (Spermophilus columbianus) show evidence of costs of reproduction. Behav Ecol Sociobiol 48:75-83. https://doi.org/10.1007/s002650000209

Neumann C, Duboscq J, Dubuc C, Ginting A, Maulana A, Agil M, Widdig A, Engelhardt A (2011) Assessing dominance hierarchies: validation and advantages of progressive evaluation with Elo-rating. Anim Behav 82:911-921. https://doi.org/10.1016/j. anbehav.2011.07.016

Nieuwenhuis R, Grotenhuis M, Pelzer B (2012) influence.ME: tools for detecting influential data in mixed effects models. R J 4:3847. https://doi.org/10.32614/RJ-2012-011

Nievergelt CM, Martin RD (1999) Energy intake during reproduction in captive common marmosets (Callithrix jacchus). Physiol Behav 65:849-854. https://doi.org/10.1016/s0031-9384(98) 00249-2

Nurmi NO, Hohmann G, Goldstone LG, Deschner T, Schülke O (2018) The "tolerant chimpanzee"- towards the costs and benefits of sociality in female bonobos. Behav Ecol 29:1325-1339. https://doi.org/10.1093/beheco/ary118

Oftedal O, Boness D, Tedman R (1987) The behavior, physiology, and anatomy of lactation in the Pinnipedia. Curr Mammal 13:175-245. https://doi.org/10.1007/978-1-4757-9909-5_6

Ostner J, Heistermann M, Schülke O (2008) Dominance, aggression and physiological stress in wild male Assamese macaques (Macaca assamensis). Horm Behav 54:613-619. https://doi. org/10.1016/j.yhbeh.2008.05.020

Ostner J, Schülke O (2018) Linking sociality to fitness in primates: a call for mechanisms. Adv Stud Behav 50:127-175. https:// doi.org/10.1016/bs.asb.2017.12.001

Payne PR, Wheeler EF (1968) Comparative nutrition in pregnancy and lactation. Proc Nutr Soc 27:129-138. https://doi.org/10. 1079/PNS19680037 
Prentice AM, Prentice A (1988) Energy costs of lactation. Annu Rev Nutr 8:63-79

R Core Team (2020) R: A language and environment for statistical computing. R foundation for statistical computing, Vienna, Austria, https://www.R-project.org/

Richter C, Heesen M, Nenadić O, Ostner J, Schülke O (2016) Males matter: increased home range size is associated with the number of resident males after controlling for ecological factors in wild Assamese macaques. Am J Phys Anthropol 159:52-62. https://doi.org/10.1002/ajpa.22834

Rose LM (1994) Sex differences in diet and foraging behavior in white-faced capuchins (Cebus capucinus). Int J Primatol 15:95-114. https://doi.org/10.1007/BF02735236

Sawada A, Sakaguchi E, Hanya G (2010) Digesta passage time, digestibility, and total gut fill in captive Japanese macaques (Macaca fuscata): effects food type and food intake level. Int J Primatol 32:390-405. https://doi.org/10.1007/ s10764-010-9476-5

Schielzeth H (2010) Simple means to improve the interpretability of regression coefficients. Methods Ecol Evol 1:103-113. https:// doi.org/10.1111/j.2041-210X.2010.00012.x

Schielzeth H, Forstmeier W (2009) Conclusions beyond support: overconfident estimates in mixed models. Behav Ecol 20:416-420. https://doi.org/10.1093/beheco/arn145

Schülke O, Chalise MK, Koenig A (2006) The importance of ingestion rates for estimating food quality and energy intake. Am J Primatol 68:951-965. https://doi.org/10.1002/ajp.20300

Schülke O, Pesek D, Whitman BJ, Ostner J (2011) Ecology of assamese macaques (Macaca assamensis) at Phu Phieo Wildlife sanctuary, Thailand. J Wildlife Thailand 18:1-15

Serio-Silva JC, Hernández-Salazar LT, Rico-Gray V (1999) Nutritional composition of the diet of Alouatta palliata mexicana females in different reproductive states. Zoo Biol 18:507-513. https://doi. org/10.1002/(SICI)1098-2361(1999)18:6\%3c507::AID-ZOO5\% 3e3.0.CO;2-R

Sherry DS, Ellison PT (2007) Potential applications of urinary C-peptide of insulin for comparative energetics research. Am J Phys Anthropol 133:771-778. https://doi.org/10.1002/ajpa.20562

Smithson M, Verkuilen J (2006) A better lemon squeezer? Maximumlikelihood regression with beta-distributed dependent variables. Psychol Methods 11:54-71. https://doi.org/10.1037/1082-989X. 11.1.54

Stearns SC (1992) The Evolution of Life Histories. Oxford University Press, Oxford

Tantasuparuk W, Dalin A-M, Lundeheim N, Kunavongkrit A, Einarsson S (2001) Body weight loss during lactation and its influence on weaning-to-service interval and ovulation rate in Landrace and Yorkshire sows in the tropical environment of Thailand. Anim Reprod Sci 65:273-281. https://doi.org/10.1016/S03784320(00)00218-9

Tardiff SD (1997) The bioenergetics of parental behavior and the evolution of alloparental care in marmosets and tamarins. In: Solomon NG, French JA (eds) Cooperative Breeding in Mammals. Cambridge University Press, Cambridge, pp 11-33

Thompson NA, Higham JP, Heistermann M, Vogel E, Cords M (2020) Energy balance but not competitive environment corresponds with allostatic load during development in an Old World monkey. Horm Behav 119:104664. https://doi.org/10.1016/j.yhbeh. 2019.104664

Touitou S, Heistermann M, Schülke O, Ostner J (2021) Triiodothyronine and cortisol levels in the face of energetic challenges from reproduction, thermoregulation and food intake in female macaques. Horm Behav 131:104968. https://doi.org/10.1016/j. yhbeh.2021.104968

Tsuji Y, Kazahari N, Kitahara M, Takatsuki S (2008) A more detailed seasonal division of the energy balance and the protein balance of Japanese macaques (Macaca fuscata) on Kinkazan Island, northern Japan. Primates 49:157-160. https://doi.org/10.1007/ s10329-007-0070-1

Weng R-C (2019) Dietary supplementation with different types of fiber in gestation and lactation: effects on sow serum biochemical values and performance. Asian-Australas J Anim Sci 33:1323-1331. https://doi.org/10.5713/ajas.19.0545

Wheatley KE, Bradshaw CJA, Harcourt RG, Hindell MA (2008) Feast or famine: evidence for mixed capital-income breeding strategies in Weddell seals. Oecologia 155:11-20. https://doi.org/10.1007/ s00442-007-0888-7

Xia Y, Sun J, Chen D-G (2018) Statistical Analysis of Microbiome Data with R. Springer, Berlin

Zhuo Y, Feng B, Xuan Y, Che L, Fang Z, Lin Y, Xu S, Li J, Feng B, Wu D (2020) Inclusion of purified dietary fiber during gestation improved the reproductive performance of sows. J Anim Sci Biotechnol 11:47. https://doi.org/10.1186/s40104-020-00450-5

Ziegler T, Hodges K, Winkler P, Heistermann M (2000) Hormonal correlates of reproductive seasonality in wild female hanuman langurs (Presbytis entellus). Am J Primatol 51:119-134. https:// doi.org/10.1002/(SICI)1098-2345(200006)51:2\%3c119::AIDAJP2\%3e3.0.CO;2-O

Publisher's note Springer Nature remains neutral with regard to jurisdictional claims in published maps and institutional affiliations. 